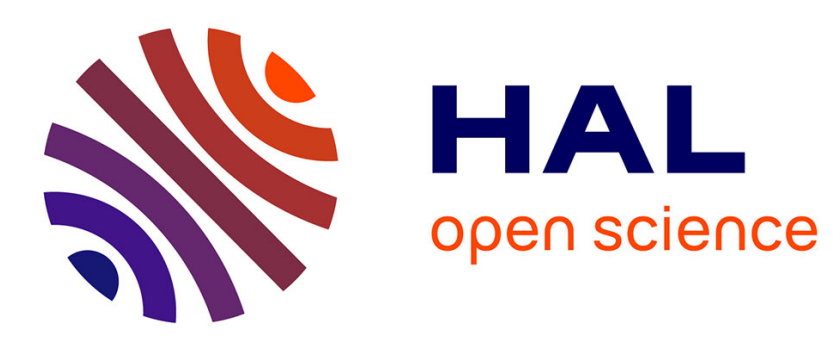

\title{
Progress in the development of polymeric and multifunctional photoinitiators
}

Junyi Zhou, Xavier Allonas, Ahmad Ibrahim, Xiaoxuan Liu

\section{To cite this version:}

Junyi Zhou, Xavier Allonas, Ahmad Ibrahim, Xiaoxuan Liu. Progress in the development of polymeric and multifunctional photoinitiators. Progress in Polymer Science, 2019, 99, pp.101165 10.1016/j.progpolymsci.2019.101165 . hal-03488558

\section{HAL Id: hal-03488558 \\ https://hal.science/hal-03488558}

Submitted on 21 Dec 2021

HAL is a multi-disciplinary open access archive for the deposit and dissemination of scientific research documents, whether they are published or not. The documents may come from teaching and research institutions in France or abroad, or from public or private research centers.
L'archive ouverte pluridisciplinaire HAL, est destinée au dépôt et à la diffusion de documents scientifiques de niveau recherche, publiés ou non, émanant des établissements d'enseignement et de recherche français ou étrangers, des laboratoires publics ou privés.

\section{다)(1) $(5$}

Distributed under a Creative Commons Attribution - NonCommercial| 4.0 International 


\title{
Progress in the Development of Polymeric and Multifunctional Photoinitiators
}

\author{
Junyi Zhou, ${ }^{\dagger}$ Xavier Allonas, ${ }^{* \dagger}$ Ahmad Ibrahim,${ }^{\dagger}$ Xiaoxuan Liu ${ }^{*}, \pitchfork$
}

$\dagger$ Guangdong Provincial Key Laboratory of Functional Soft Condensed Matter, Department of Polymeric Materials and Engineering, School of Materials and Energy, Guangdong University of Technology, Guangzhou, P.R. China

₹ Laboratory of Macromolecular Photochemistry and Engineering University of Haute-Alsace, Mulhouse 68093, France

\begin{abstract}
:
UV-curing technology has been developed and widely used in industry for 6 decades. However, the migration of low-molecular-weight photolysis is today an important drawback in many application fields such as food packaging materials, leading to unpleasant secondary features such as odor, blooming and contamination. Therefore, many efforts have been devoted to design polymeric photoinitiators (PPIs) and multifunctional photoinitiators (MFPIs) to overcome these drawbacks. This review introduces the development and the challenges of UV-curing technology and the state of the art of PPIs and MFPIs, in which methodologies of synthesis and characterization are meticulously discussed. Moreover, a novel classification, based on the molecular structure, has been drafted for all the PPIs conventionally reacting through photodissociation or photoreduction. Most of the PPIs and MFPIs have excellent photochemistry properties, some of which have extra properties such as amphiphile, self-floating and biocompatibility. Examples of well-defined structures are discussed in the section on MFPIs.
\end{abstract}

Keywords: photopolymerization, polymeric photoinitiator, multifunctional photoinitiator, free radical, migration

Corresponding Author: xavier.allonas@uha.fr 


\section{Abbreviations}

AA Acrylic acid

ABPE-10 2,2-Bis[4-(acryloxypolyethoxy) phenyl]propane

AM Acrylamide

AMP-10G Phenoxy ethyleneglycol acrylate

AN Acrylonitrile

An

Anthracene

ATRP Atom transfer radical polymerization

BA Butyl Acrylate

BP Benzophenone

CEVE 2-Chloroethylvinyl ether

$\mathrm{CHO} \quad$ Cyclohexene oxide

DBC Double bond conversion

DEAB 4,4' Bis (diethylamino) benzophenone

DMAB 4-(Dimethylamino) benzophenone

EA Ethylacrylate

EPOX (3,4-Epoxycyclohexane)methyl

3,4-epoxycyclohexylcarboxylate

HCPPI Hyperbranched and cross-linked polymeric photoinitiator

HDDA Hexanediol diacrylate

HEMA 2-Hydroxyethyl methacrylate

HMPP 2-Hydroxy-2-methyl-1-phenylpropanone

IPDI Isophorone diisocyanate

ITX Isopropylthioxanthone

LFP Laser flash photolysis

LOD Limit of detection

LOQ Limit of quantification

LPPI Linear polymeric photoinitiator

MFPI Multifunctional photoinitiator
MK Michler ketone

MMA Methylmethacrylate

MW Molecular weight

NMP Nitroxide mediated polymerization

NVP N-Vinylpyrrolidone

PDI Polydispersity index

PEG Poly(elthylene glycol)

PEGDA Polyethyleneglycol diacrylate

PETA Pentaerythritol tri-, tetra- acrylate

PI Photoinitiator

PPGDA Poly(propylene glycol) diacrylate

PPI Polymeric photoinitiator

PU Polyurethane

Py Pyrene

RAFT Reversible addition fragmentation chain-transfer

RASFF Rapid Alert System for Food and Feed

RDRP Reversible-deactivation radical

polymerization

St Styrene

TDI Toluene-2,4-diisocyanate

THFA Tetrahydrofurfuryl acrylate

TMPTA Trimethylolpropane triacrylate

TPGDA Tripropylene glycol diacrylate

TPO Trimethylbenzoyldiphenylphosphine oxide

TX Thioxanthone

UV Ultraviolet

VCHD 4-Vinylcyclohexene dioxide

VOC Volatile organic compound

VP 1-Vinyl-2-p 


\section{Contents}

1. Introduction

2. Classification of polymeric photoinitiators

3. General methodologies of synthesis of PPIs

3.1 Ring-opening polymerization (M1)

3.2 Alcoholysis/aminolysis of isocyanates (M2)

3.3 ATRP from bromo-substituted PIs

3.4 Click chemistry

4. Linear Polymeric Photoinitiators (LPPIs)

4.1 In-chain LPPIs

4.2 Side-chain LPPIs

5. Hyperbranched and Cross-linked Polymeric Photoinitiators (HCPPIs)

6. Multifunctional Photoinitiators (MFPIs)

7. Migration testing for measuring UV photoinitiators

8. Perspectives and outlook 


\section{Introduction}

Economy, efficiency, ecology and energy are the "4E" principles of modern industrial development. UV-curing technology is widely studied among coatings, adhesives and inks manufacturers, because of its compliance with these principles. Compared to thermal curing system, UV-curing process has attractive advantages such as high-speed, low energy consumption and low-solvent formulation [1-2]. Between the two main types of UV-curing mechanism (radical-type and cationic-type), the radical-type systems are the most widely used in UV-curing application so far in virtue of their higher reactivity [1,3].

Radiation curing has gained popularity in the packaging printing industry over the last decades, since it was commercialized in the late 1960s. Using ultraviolet (UV) energy to trigger polymerization of resins onto a substrate, UV-curing technique has been used in inks and coatings for food packaging printing, such as breakfast cereal boxes, milk and fruit juice cartons, frozen dinner cartons, ice cream and frozen dessert packages, as well as flexible film wraps. UV curing affords distinct advantages: fast curing, room temperature operation, high quality end products and low cost. In addition, UV curing technology is generally performed under room temperature conditions and thus allows the application of inks and coatings on heat sensitive substrates. Moreover, UV-cured formulations can be directly applied to the outer surface of the package without the use of solvents, hence reducing drying time and eliminating solvent exposure to workers.

In UV curing, acrylate monomers and oligomers are predominantly used to form a polymer resin due to the rapic reaction rates and the high degree of optical clarity of the end products. The acrylate monomers are primarily used as diluents, to impart the rheological properties necessary for the printing and coating process [4]. Many types of curable acrylate monomers are available commercially. For instance, there are acrylate monomers like tripropylene glycol diacrylate 
(TPGDA), trimethylolpropane triacrylate (TMPTA), hexanediol diacrylate (HDDA) and pentaerythritol tri-, tetra acrylate (PETA) etc.

Photoinitiators (PIs), the agents that absorb the UV energy and form free radicals that initiate the polymerization reaction, are the key compounds in UV-curing formulations. According to the free radical forming mechanism, the PIs can be classified to Type-I PIs and Type-II PIs [1-2]. Type-I PIs lead to photodissociation, creating two radicals that may both initiate the polymerization reaction. Type-II PIs undergo photoreduction reaction by reaction with an electron or hydrogen donor. Thus, they require an additional co-initiator, such as a tertiary amine, ether, ester, or thiol for the formation of initiating radicals and low reactive ketyl radicals $[3,5]$.

Generally, the higher reactive radicals initiate the polymerization reaction and are therefore locked into the growing polymer chains after the polymerization process. Nevertheless, some of the photoproducts of PIs may exhibit varied physical and chemical properties, which can be detrimental to the efficiency of photoinitiation and the performance of the cured product. The photoproducts of both Type-I and Type-II PIs may undergo further rearrangement, combination, oxidation and decomposition due to the instability of the radicals (Scheme 1). Some of these small molecular by-products may be colored or odorous and be inclined to migration in the polymer networks [6]. The migration of the PIs fragments could bring about odor and blooming of coatings, which present problems in materials used for food packaging. A further concern are residual amounts of PIs, either as remainder of the UV-curing process or due to incomplete purification, since PI species are prone to migrate through the porous paperboard and secondary packaging to the food or beverage. They also can remain in the paperboard after the outer print layer is removed, and thus PIs can appear in new packaging made with recycled paperboard fibers [7]. 
In the last decade, several notifications reported through Rapid Alert System for Food and Feed (RASFF) in the EU were related to the PIs used for food packaging. More than one hundred notifications issued RASFF concerned the migration of PIs from food packaging since 2000. The first one corresponded to the detection of isopropylthioxanthone (ITX) in baby milk in 2005 [6,8]. That well-known "isopropylthioxanthone case" (2005) and the "benzophenone and 4-methylbenzophenone cases" (2009) led to serious consequences [8]. Soon after these events, considerable interest has been focused on side effects due to photoinitiators in the food industry, including the migration process, the analytical methods for migration and the toxicity of the photoproducts.

It is important to precise that the term "migration" also accounts for the transfer of chemicals compounds from the package to the food. Also, throughout the paper we are interested in PIs among the different components of the photopolymerizable formulations used for food packaging. A variety of factors have been shown to affect migration from the printed surface through the paperboard and to the food itself (direct contact), or from the paperboard through the vapor phase to the food (indirect contact) [7-8]. These factors include set-off [9-10], the vapor pressure of the UV photoinitiator [11], time and temperature of food storage [9-10,12], porosity and types of materials used for primary and secondary packaging, the fat and moisture content of the food, and whether the UV photoinitiator is present or not in recycled materials used to form new packaging. 


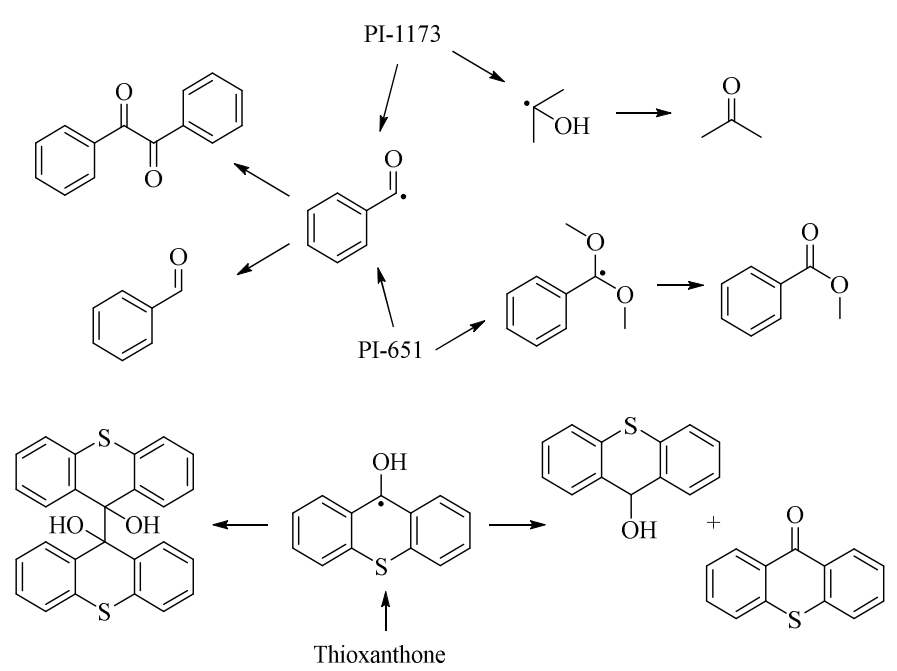

Scheme 1. Several examples of secondary reactions of photoinitiators.

PIs with high molecular weight (MW) are believed to be a promising solution to the above problem, among those polymeric photoinitiators (PPIs) and multifunctional photoinitiators (MFPIs) are major topics of discussion. The idea of grafting the PIs on a high MW molecule is aimed at anchoring the odorous or toxic photoproducts. Previous review articles introduce the synthesis and performance of various macromolecules bearing Type-I or Type-II PI groups such as benzoin ether and thioxanthone [13]. However, there have been increasing numbers of PPIs and MFPIs with all sorts of molecular structures. Therefore, the existing definition and classification of these PIs needs to be reappraised.

Many efforts have been devoted to the development of PPIs and MFPIs including synthesis routes, photoinitiating performances and structural functionalities. This systematic review introduces the recent advances of PPIs and MFPIs, and drafts an innovative categorization for them. PPIs are distributed according their molecular structure into three classes: linear polymeric photoinitiator (LPPI), hyperbranched or cross-linked polymeric photoinitiator (HCPPI), and multifunctional photoinitiator (MFPI). In the scope of this discussion, the initiation systems of 
low-MW Type-II PI with polymer hydrogen donor and the self-photoinitiation of monomer bearing PI group are not included, notwithstanding their prosperous application.

\section{Classification of polymeric photoinitiators}

Many different strategies can be used to develop new polymeric photoinitiators leading to a wide variety of structures. Therefore, when dealing with PPIs, it is convenient to separate a) the photoinitiator moiety, which is quite often based on well-known low molecular weight photoinitiators and b) the polymeric backbone that does not influence the absorption of light and the mechanism of reaction.

Concerning the photoinitiator moiety, one has to say that most of the polymeric photoinitiators are based on well-known low molecular weight photoinitiators. Therefore, the photoinitiation mechanisms are expected to be quite similar to the parent molecules. From that point of view, photoinitiators are generally divided into two families: Type-I and Type-II photoinitiators.
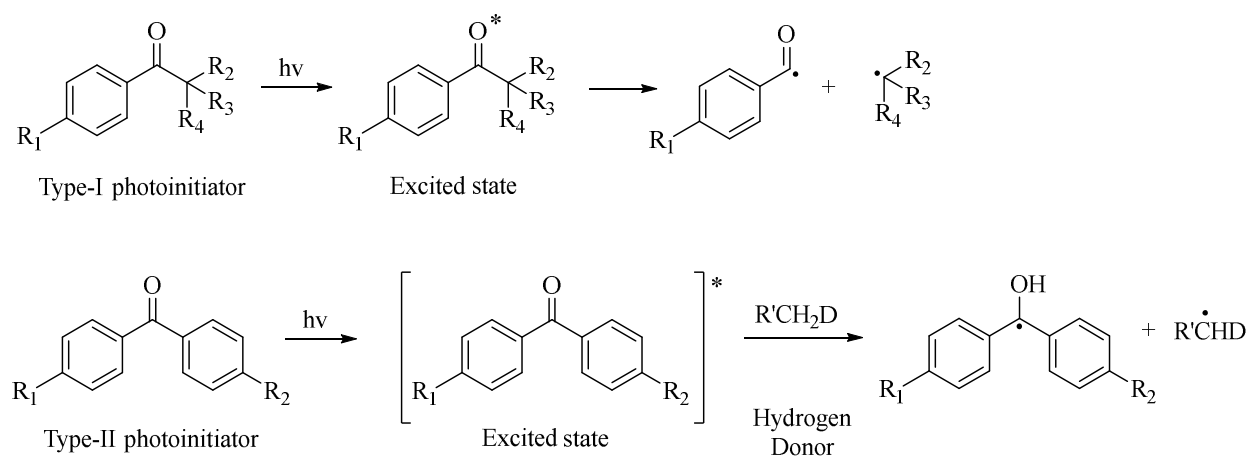

Scheme 2. Reaction mechanisms of Type-I and Type-II photoinitiators.

Type-I PIs absorb radiation and undergo bond cleavage from an excited state providing initiating radicals, while Type-II PIs undergo hydrogen abstraction from a coinitiator (hydrogen 
donor), which results in two free radical species (Scheme 2). The photoinduced homolytic cleavage of Type-I PIs could occur at the $\alpha$-position (major) or $\beta$-position (minor) of carbonyl group, depending on their bond strengths. As for Type-II PIs, a co-initiator, such as tertiary amine, ether, ester, thiol, etc., is needed to donate hydrogen to the triplet state PI, producing a low reactive ketyl radical and a highly reactive donor radical $[3,5]$. 
Table 1. Structures of photoinitiator moiety in PPIs and MFPIs.

L: LPPIs, H: HCPPIs, M: MFPIs

\begin{tabular}{|c|c|c|c|c|c|}
\hline \multicolumn{3}{|l|}{ Type I } & \multicolumn{3}{|l|}{ Type II } \\
\hline PI group & $\lambda_{\max }(\mathrm{nm})$ & $\overline{\text { Ref. }}$ & PI group & $\lambda_{\max }(\mathrm{nm})$ & Ref. \\
\hline & 280,330 & $\begin{array}{c}\mathrm{L}[14-19] \\
\mathrm{H}[20] \\
\mathrm{M}[21-22]\end{array}$ & $\mathrm{R}=\mathrm{U}, \mathrm{S}, \mathrm{NH}$ & $\begin{array}{l}280 \sim 290 \\
340 \sim 350\end{array}$ & $\begin{array}{l}\text { L [23-35] } \\
\mathrm{H}[36-40] \\
\mathrm{M}[41-44]\end{array}$ \\
\hline & 275,320 & $\begin{array}{c}\mathrm{L} \\
{[14,16,45]}\end{array}$ & & $\begin{array}{l}\text { 250 280, } \\
315 \sim 325\end{array}$ & L [46-49] \\
\hline & 280,325 & $\begin{array}{c}\mathrm{L}[14-16,50 \\
-53] \\
\mathrm{M}[54-56]\end{array}$ & & $315 \sim 325$ & $\begin{array}{c}\mathrm{L} \\
{[46,57-59]}\end{array}$ \\
\hline & 280,320 & $\begin{array}{c}\mathrm{L}[60-61] \\
\mathrm{H}[20]\end{array}$ & & 468 & L [62-63] \\
\hline & 290,320 & L [64-65] & & & L [66] \\
\hline & 300,340 & H [67] & & $\begin{array}{c}246 \sim 248 \\
308\end{array}$ & L [68] \\
\hline & & L [69] & $0, S, 0 \quad-\quad$, & 380 390 & $\begin{array}{l}\text { L [70-76] } \\
\text { Н [77-78] } \\
\text { М [79-83] }\end{array}$ \\
\hline
\end{tabular}




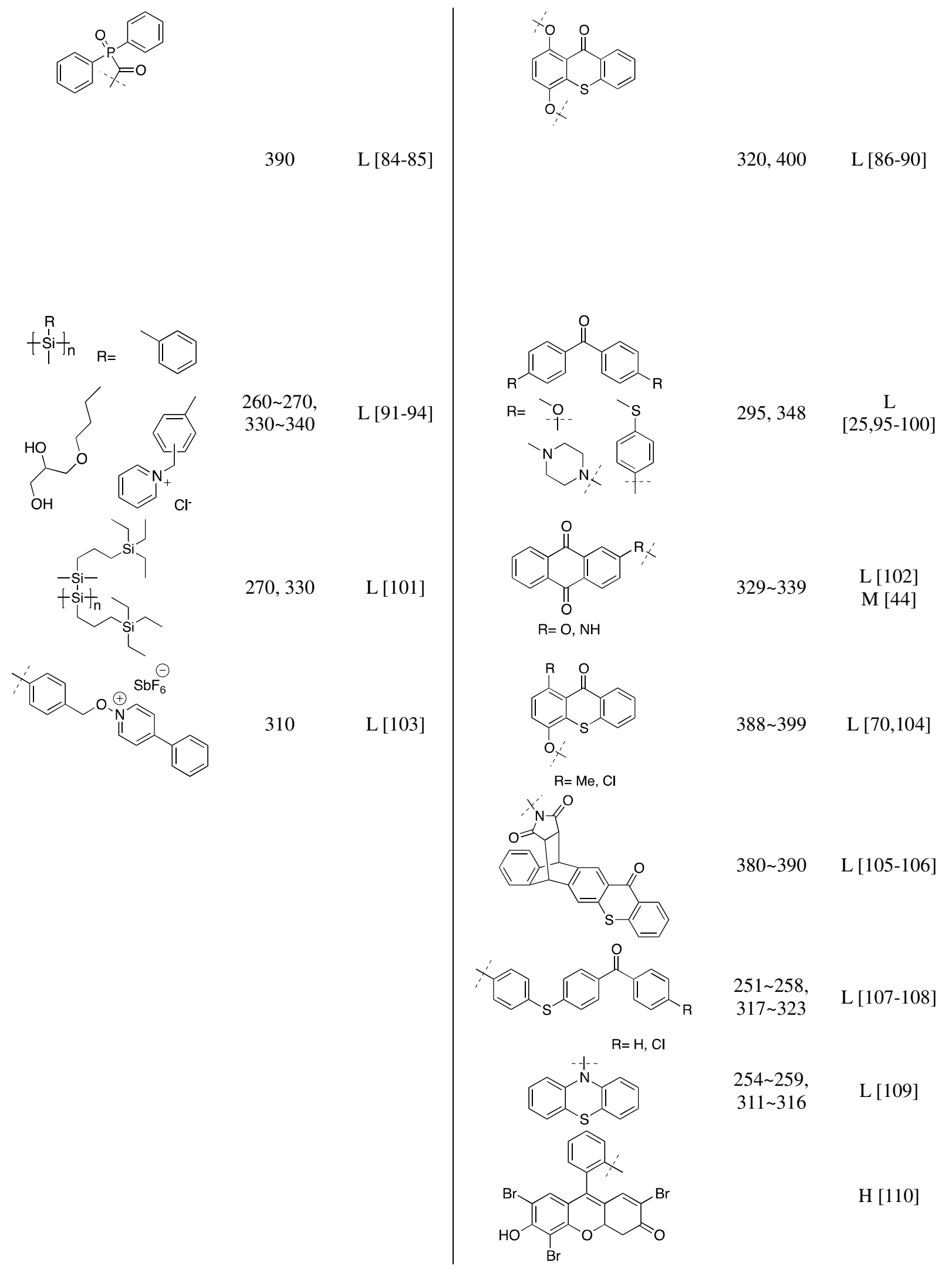




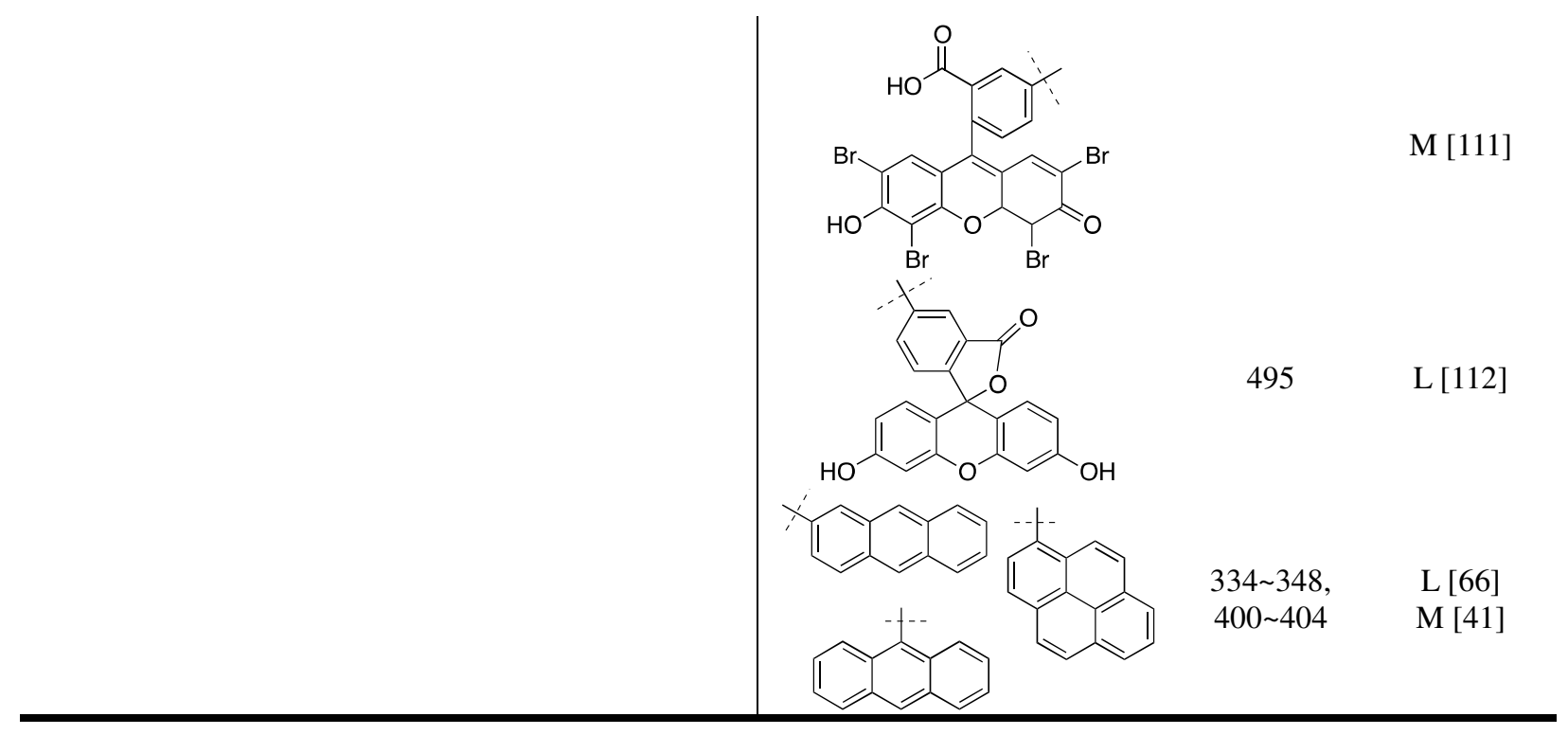

Table 1 collects the different photoinitiator structures that have been used to synthesize PPIs, while Table 2 includes the $\mathrm{DBC}$ of acrylate monomers that initiated by those PPIs. The photochemistry of these photoinitiators groups is well known and will not be discussed as the reaction mechanism have been described elsewhere [1-3,5].

Next to the photoinitiator moiety, the polymer backbone plays an important role. Indeed, the ease of synthesis, the viscosity, and the solubility properties will control the effectiveness of the PPI. For sake of clarity, it is worth classifying the different kind of polymeric structures that could be found in the literature. 
Table 2. Structures of photoinitiator moiety in PPIs and MFPIs and the final DBC of the employed monomers. L : LPPIs, H : HCPPIs, M : MFPIs

\begin{tabular}{|c|c|c|c|}
\hline PI group & Monomer & $\begin{array}{l}\text { Final Conversion } \\
(\%)\end{array}$ & Ref \\
\hline & $\begin{array}{l}\text { L: MMA } \\
\text { H:EA }\end{array}$ & $\begin{array}{l}14.5-21.0 \\
88.0\end{array}$ & $\begin{array}{c}15-16 \\
21\end{array}$ \\
\hline & $\begin{array}{l}\mathrm{L}: \mathrm{MMA} \\
\mathrm{CHO}\end{array}$ & $\begin{array}{c}14.0 \\
16.0-22.0\end{array}$ & $\begin{array}{l}16 \\
45\end{array}$ \\
\hline & $\begin{array}{c}\text { L: MMA } \\
\text { AN } \\
\text { AM } \\
\text { HDDA } \\
\text { M: TMPTA } \\
\text { Ebecryl } 605\end{array}$ & $\begin{array}{c}15.0-21.0 \\
17.5 \\
17.0-28.2 \\
65.0 \\
45.0 \\
69.2-95.0\end{array}$ & $\begin{array}{c}16,51-52 \\
50 \\
50,52 \\
53 \\
54 \\
55-56\end{array}$ \\
\hline & $\begin{array}{c}\text { L: MMA } \\
\text { St } \\
\text { H: EA }\end{array}$ & $\begin{array}{c}46.0-49.0 \\
10.0 \\
88.0\end{array}$ & $\begin{array}{l}60 \\
61 \\
20\end{array}$ \\
\hline & L: HDDA & $30.0-40.0$ & $64-65$ \\
\hline & H: MMA & 50.0 & 67 \\
\hline & $\begin{array}{c}\mathrm{L}: \mathrm{MMA} \\
\mathrm{St}\end{array}$ & $\begin{array}{l}12.0-40.0 \\
15.0-34.0\end{array}$ & $\begin{array}{l}69 \\
69\end{array}$ \\
\hline & $\begin{array}{c}\text { L: HEMA } \\
\text { HEMA/H2O } \\
\text { HDDA/BA }\end{array}$ & $\begin{array}{c}48.0-82.0 \\
102.0-116.0 \\
4.0-20.0\end{array}$ & $\begin{array}{l}84 \\
84 \\
85\end{array}$ \\
\hline & $\begin{array}{c}\mathrm{L}: \mathrm{AM} / \mathrm{H} 2 \mathrm{O} \\
\text { HEMA } \\
\text { AA }\end{array}$ & $\begin{array}{c}80.0-100 \\
>90.0 \\
>90.0\end{array}$ & $\begin{array}{l}94 \\
94 \\
94\end{array}$ \\
\hline & L: TMPTA & 59.0 & 101 \\
\hline
\end{tabular}




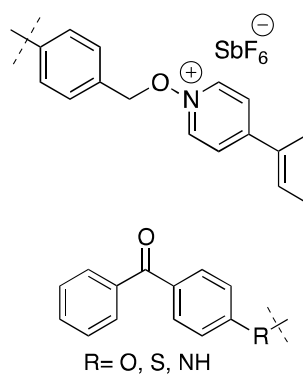

$\begin{array}{ccc}\text { L: MMA } & 56.0-79.0 & 103 \\ & & \\ & & \\ & & \\ & & \\ \text { L: TMPTA } & 20.0-55.0 & 24,26,33-34 \\ \text { HDDA } & 60.0-95.0 & 26,32,35 \\ \text { TPGDA } & 40.0-90.0 & 27-29,31,33 \\ \text { MMA } & 0.5-30.6 & 32,35 \\ \text { THFA } & 98.0 & 33 \\ \text { TEGDMA } & 50.0-72.0 & 32-35 \\ \text { PETA } & 30.0 & 38 \\ \text { HEMA } & 85.0 & 35 \\ \text { H: TMPTA } & 44.1-58.9 & 38 \\ \text { HDDA } & 44.3-76.2 & 39-40 \\ \text { M: EPOX } & 90.0 & 41 \\ \text { TMPTA } & 20.0 & 41\end{array}$

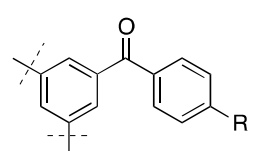

$\mathrm{s}_{\mathrm{S}^{\prime}}^{\mathrm{R}=}$<smiles>CC(C)(C)c1ccc(Pc2ccc(C(=O)c3ccc(C(C)(C)C)cc3)cc2)cc1</smiles>

$\mathrm{R}=\mathrm{O}, \mathrm{S}$<smiles>CC1(C)C2CCC1(CI)C(=O)C2=O</smiles><smiles>CC(C)(C)Oc1ccc(C(=O)c2ccccc2)c(OC(C)(C)C)c1</smiles><smiles>C[Y](C)c1ccc2sc3ccccc3c(=O)c2c1</smiles>

$\mathrm{R}=\mathrm{O}, \mathrm{S}, \mathrm{CH}_{2}, \mathrm{CH}$
L: EA

PPGDA

TMPTA

PU prepolymer

L: EA

PPGDA

TMPTA

PU prepolymer

L: HDDA/BA

L: PPGDA

TMPTA

L: TMPTA
MMA

AM

NVP

HEMA

H: AM

PEGDA

A-BPE-10

M: AM

MMA

TMPTA

AM

A-BPE-10
9.4-15.4

$59.8-86.2$

32.6-59.9

28.7-97.3

11.3-15.3

41.5-80.3

36.5-53.9

61.3-86.7

$3.0-65.0$

85.4-93.4

63.2-68.0

$85.7-100.0$

14.0-26.1

27.7-48.0

62.3-83.4

85.4-87.1

$78.7-86.0$

$>20.0$

$0-41.5$

60.0

$>50.0$

54.7-89.4
63

68

68

71

72,75

74,75

75

46
46

46-49

47-49

46 46,58

$46-58$
57

$$
63
$$

75

77

77

77

79

80,82

80

81

83 

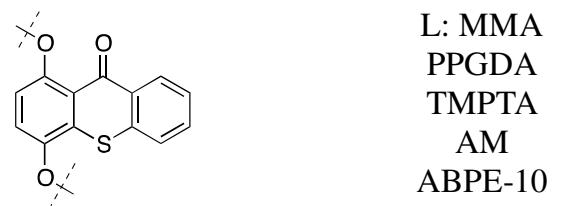

$>25.0$
$9.9-51.7$
$31.8-54.1$
54.2
79.3

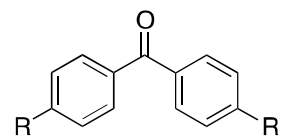

L: PPGDA

65.8-76.2

AMP-10G

$20.0-78.5$

A-BPE-10

74.1-88.8

40.5

$R=\begin{array}{ccc}0 & \text { TMPTA } \\ -1 & & \text { HDDA }\end{array}$

12.0-65.0

PEGDA

66.7-94.2

90

90<smiles></smiles>

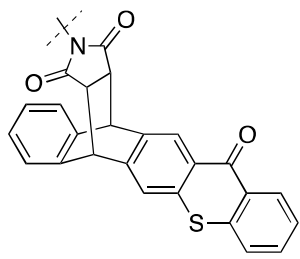

L: MMA

0.3-20.0

70.0

69.0

73.0

72.0

95

97

98,100

98

99

100

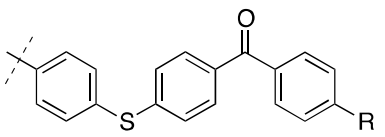

L: HDDA

71.2-98.1

45.6-76.3

$107-108$

TMPTA

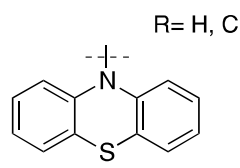

L: CEVE

95.0

109

VCHD

80.0-90.0

$\mathrm{H}: \mathrm{St}$

2.2

110

AM

87.4

110

AN

38.4

110<smiles>O=C1C=C2C=C(Br)C=C3c4cc(Br)c(O)c(Br)c4OC(C1)C23</smiles>

AA

4.8

110

EPOX

$55.0-80.0$

41

The classification in this review is based on the variety of molecular configurations of photoinitiator moieties and backbones (Figure 1). Since the photoinitiator groups are the substantial parts in PPIs and MFPIs, a discussion of the backbone structures has not been the interest of researchers. In most cases, the motivation for considering the backbone structure would be related tof the ease of synthesis of the respective structure. This will be discussed in the 
following sections. Nevertheless, some peculiar backbones either have certain functionalities [51,55-57,86-87] or affect the photochemistry of the photoinitiator groups [102].

LPPI refer to the linear polymer bearing PI groups either as "in-chain LPPIs" which include the PI as a part of the linear chain or as "side-chain LPPIs" in which the PI is connected to the polymer backbone as a pending group.

Highly cross-linked polymeric photoinitiator (HCPPI) refers to uncountable PI groups grafted either on hyperbranched polymer or on polymeric cross-linked network. By contrast, multifunctional polymeric photoinitiator (MFPI) refers to defined number of PI groups locating at relatively low-molecular-weight core or dendrimer.

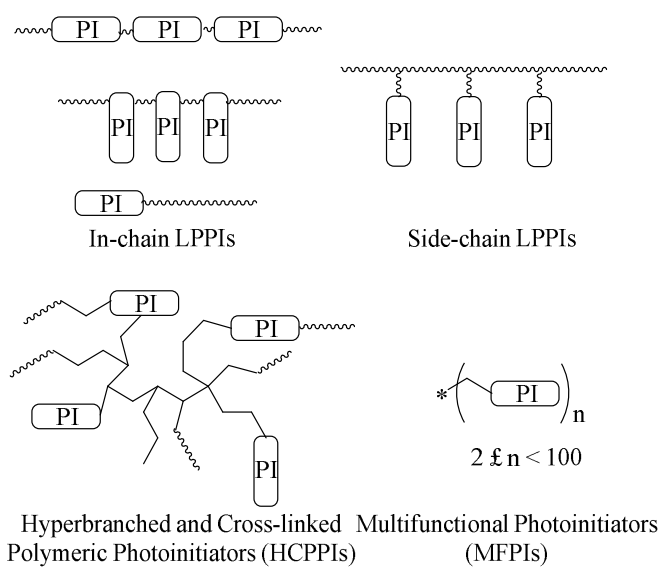

Figure 1. Structural distinction of in-chain LPPI, side-chain LPPI, HCPPI and MFPI according to the classification of this review.

\section{General methodologies of synthesis of PPIs}


The first question when one designs the synthesis route of a new PPI would be: how to install an effective PI on a polymer and preserve it during the preparation step? This question implies two different ways of constructing PPIs, which are represented by "preserve" and "install". Generally, PI groups can survive in most of the non-photoinduced polymerization as part of starting formulation, and be located in polymeric structure, which is one way to construct PPIs. Grafting PI groups on a ready-made polymer is another way to prepare PPIs, which is unrestricted in polymerization method but demands particular functional groups on both polymer and PI. In accordance with those ideas, several methods have been explored and used in preparation of PPIs.

\subsection{Ring-opening polymerization (M1)}

Ring-opening polymerization is one of the most versatile methods in living polymerization. Epoxides and lactones are the most popular cyclic monomers for synthesis such PPIs. Additionally, PPIs can have different functionality depending on the structure of the starting PI moiety (Scheme 3). For example, employing 1-hydroxycyclohexyl phenyl ketone, known as a commercial PI "Irgacure 184", as a starting hydroxyl source, Degirmenci [14,16] synthesized poly( $\varepsilon$-caprolactone)s via ring-opening polymerization catalyzed by $\operatorname{Sn}(\mathrm{Oct})_{2}$ with PDIs lower than 1.50. Recently, D,L-lactide has also been used as a ring-opening monomer to prepare "mid-chain" PPIs [19]. A novel biobased and environmental friendly LPPIs of poly(D,L-lactide) homopolymer and tetrablock poly(D,L-lactide)-poly(e-caprolactone) copolymer with controlled molecular weights and narrow molecular weight distributions via M1 were prepared. Jiang et al. modified thioxanthone [88] and benzophenone $[68,95,98]$ to difunctional monomers, and then synthesized a series of PPIs with PI groups in the repeat units. 


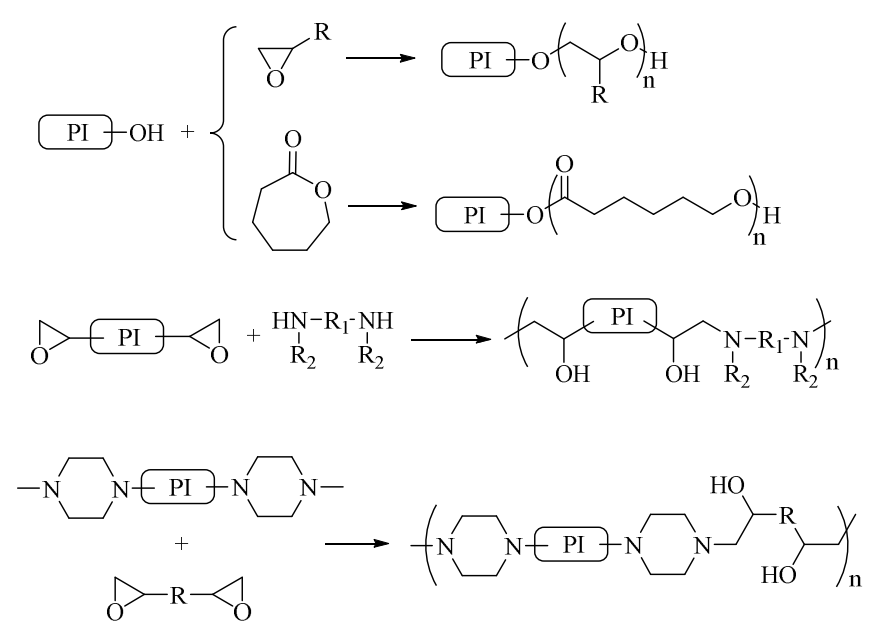

Scheme 3. Resin-like PPIs formed from ring opening polymerization.

\subsection{Alcoholysis/aminolysis of isocyanates (M2)}

Isocyanates have been widely used in preparation of oligomer, thanks to the high reactivity with hydroxyl and amino groups. In addition, this reaction does not require any catalyst and produces no by-product. This makes these reactions quite suitable for industrial manufacturing. When modified with two hydroxyl or amino groups, PIs can copolymerize with commercial isocyanates such as IPDI and TDI, forming PPIs with polyurethane or polyurea backbones (Scheme 4). Wei et al. [46-49,59] designed a two-step copolymerization among hydroxyl, amino and isocyanate compounds, preparing varied PPIs with both benzophenone derivatives and amino coinitiators on the back bones (Scheme 8b).

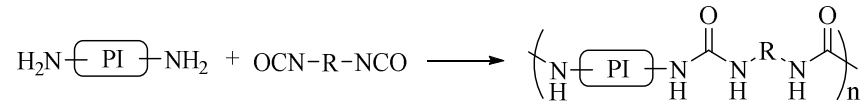

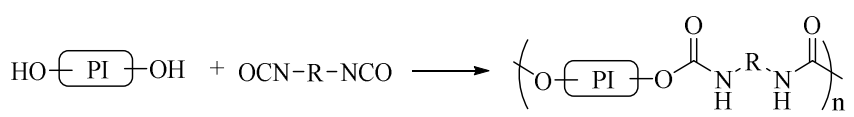

Scheme 4. Resin-like PPIs formed from alcoholysis/aminolysis of isocyanate. 


\subsection{ATRP from bromo-substituted PIs}

The methods M1 and M2 mentioned above are both facile methods that should be considered in industrial manufacturing. From a laboratory standpoint, controlled reversible-deactivation radical polymerization (RDRP) affords easy way to control the PPI structure. Among those approaches, atom transfer radical polymerization (ATRP) has been employed in synthesis of PPIs. In the basic ATRP equilibrium, redox-active transition metal complexes are involved as catalyst, among which the $\mathrm{Cu} / \mathrm{L}$ and $\mathrm{X}-\mathrm{Cu}{ }^{\mathrm{II}} / \mathrm{L}$ are the most often used [113]. Additionally, alkyl halides act as initiators and dormant species that periodically react with the catalyst. Due to that specific equilibrium, polymers formed via ATRP bear haloalkanes after the removal of the catalyst system, which are the tiniest "tails" in RDRP family. Not only narrow molecular weight distribution [14-15,61], and block copolymer [16,69], but also possibility of further end group modification [114-115] can be achieved with ATRP. In the case of PPIs preparation, although there are other techniques, such as the well-known reversible addition fragmentation chain-transfer (RAFT) and nitroxide mediated polymerization (NMP) in RDRP to satisfy the similar requirement on general circumstance, the photo- or thermal stability of their dormant species are incomparable to those of ATRP in photosensitive system, which can be the reason why reports of RAFT and NMP are seldom seen on the topic of PPIs (Scheme 5).

$$
\begin{aligned}
& \underset{\mathrm{R}-\mathrm{P}-\mathrm{O}^{\prime}}{\stackrel{\mathrm{R}_{1}}{\mathrm{~N}}-\mathrm{R}_{2}} \stackrel{\text { Heat }}{\longrightarrow} \mathrm{R}-\mathrm{P}_{\mathrm{n}} \cdot+\stackrel{\mathrm{R}_{1}}{\mathrm{~N}-\mathrm{R}_{2}} \quad \text { Nitroxide-Mediated } \\
& \mathrm{R}-\mathrm{P}_{\mathrm{n}}-\mathrm{X} \underset{\text { Heat }}{\stackrel{\mathrm{Cu}(\mathrm{I}) \mathrm{X} / \text { Ligand }}{\longrightarrow} \mathrm{R}-\mathrm{P}_{\mathrm{n}} \cdot+\mathrm{Cu}(\mathrm{II}) \mathrm{X}_{2} / \text { Ligand }} \begin{array}{l}
\text { Atom Transfer Radical } \\
\text { Polymerization (ATRP) }
\end{array}
\end{aligned}
$$

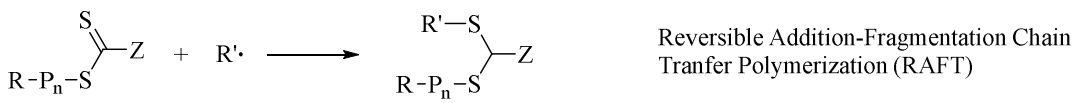

Scheme 5. Chemical properties of dormant species of different RDRP approaches. 


\subsection{Click chemistry}

Click chemistry had been an advanced tool in both polymerization and polymer modification. By simple and fast procedures, various products have been synthesized at high yield. More and more reactions are being found to match the concept of click chemistry, offering more options for construction of macromolecules (Figure 2).

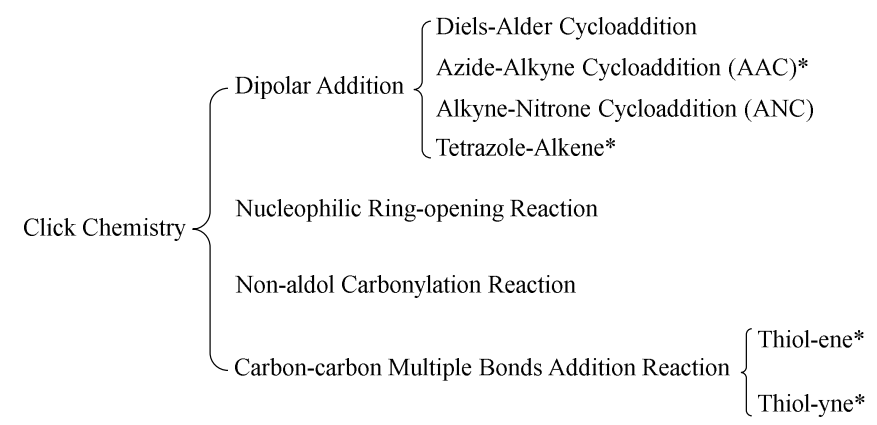

Figure 2. Classification of Click Chemistry (* photo-induced reaction has been reported).

In preparation of PPIs, the most classic example of polymer click reaction is thiol-ene polymerization, which was applied by Temel et al. to synthesize benzophenone-based PPI [99]. Moreover, copper(I)-catalyzed Huisgen dipolar cycloaddition was employed for grafting PI groups to polymer end group by Degirmenci et al. [45] Diels-Alder reaction is also one of the important click reactions to modify polymer end groups with PI groups (Scheme 6) [106]. 

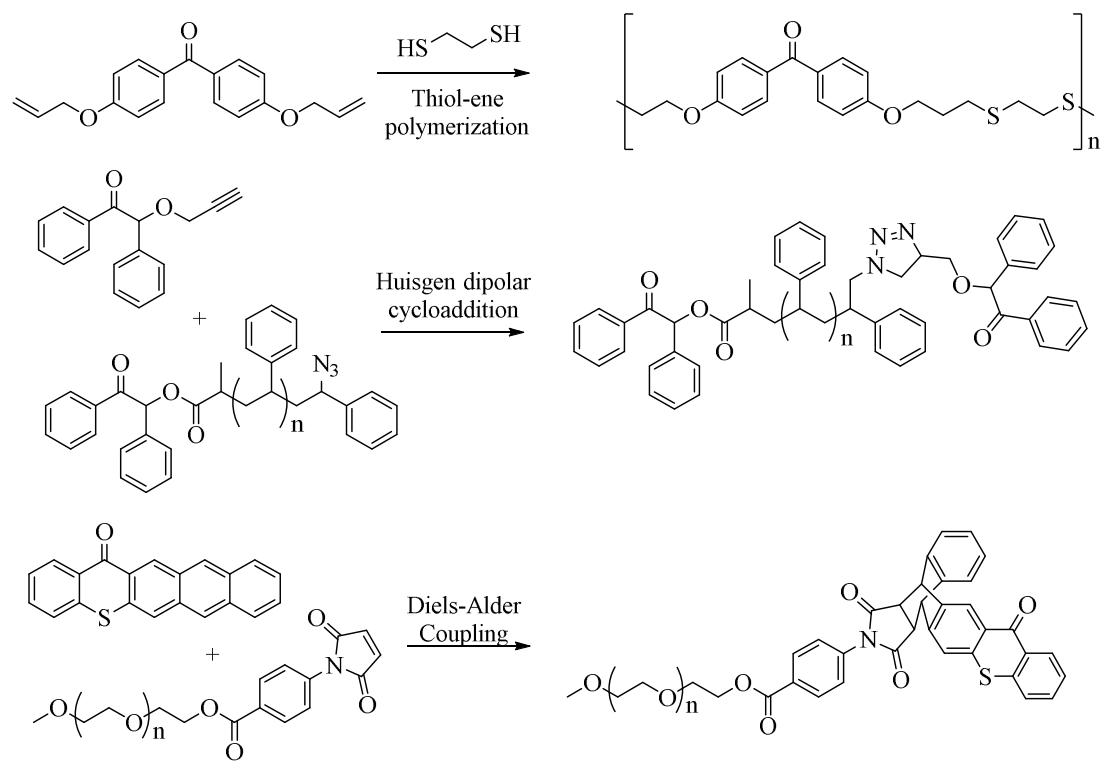

Scheme 6. Click reactions for synthesizing polymeric photoinitiators.

\section{Linear Polymeric Photoinitiators (LPPIs)}

Linear polymers are among one of the most common type of macromolecules in both scientific and industrial area. Introducing photoinitiators (Type-I or Type-II) to linear polymers is a facile way to obtain PPIs, for example, by polymerization of monomers bearing PI groups. In this way, the PI groups can be located in the backbone or the side chain of the polymer as part of the repetitive unit. Besides, modification of end-group is another route to prepare LPPIs. Nevertheless, the convenience of synthesis is not the only merit of LPPIs. The structural nature of linear polymer also benefits to the properties and the application of LPPIs.

\subsection{In-chain LPPIs}

According to our definition of in-chain LPPIs, it is obvious that the conjunction system of PI is part of the polymer backbone. Most of these LPPIs bearing Type-I PI groups, in this case, would be degraded along with photolysis of PI groups. 
The facile methodologies mentioned had not hindered the development of synthesis of In-chain LPPIs. Karasu et al. [73] adopted 2-mercapto thioxanthone as a chain transfer agent in polymerization of styrene ( $\mathrm{St}$ ) and methyl methacrylate (MMA), leading to the formation of polymers with thioxanthone (TX) end groups (Figure 7a). More recently, Yilmaz et al. [75] reported a similar PPI prepared by counterion incorporation of TX and polymer, which can be applied in either organic or aqueous system (Figure 7b). Degirmenci et al. [50-52] developed a $\mathrm{Ce}(\mathrm{IV}) / \mathrm{HNO}_{3}$ redox initiation system to prepare polymers with PIs in mid-chain (Figure $7 \mathrm{c}$ ). In this case, 2-hydroxy-1-[4-(2-hydroxyethoxy) phenyl]-2-methyl propan-1-one, was used as initiator due to its dihydroxyl functionality. Also benefit from the hydroxyl functionality, 4-hydroxybenzophenone and 4,4'-dihydroxybenzophenone were modified with 2-bromopropionyl bromine by Temel et al. [25] followed by ATRP to form end-functionalized and mid-functionalized polymers (Figure $7 d$ ).
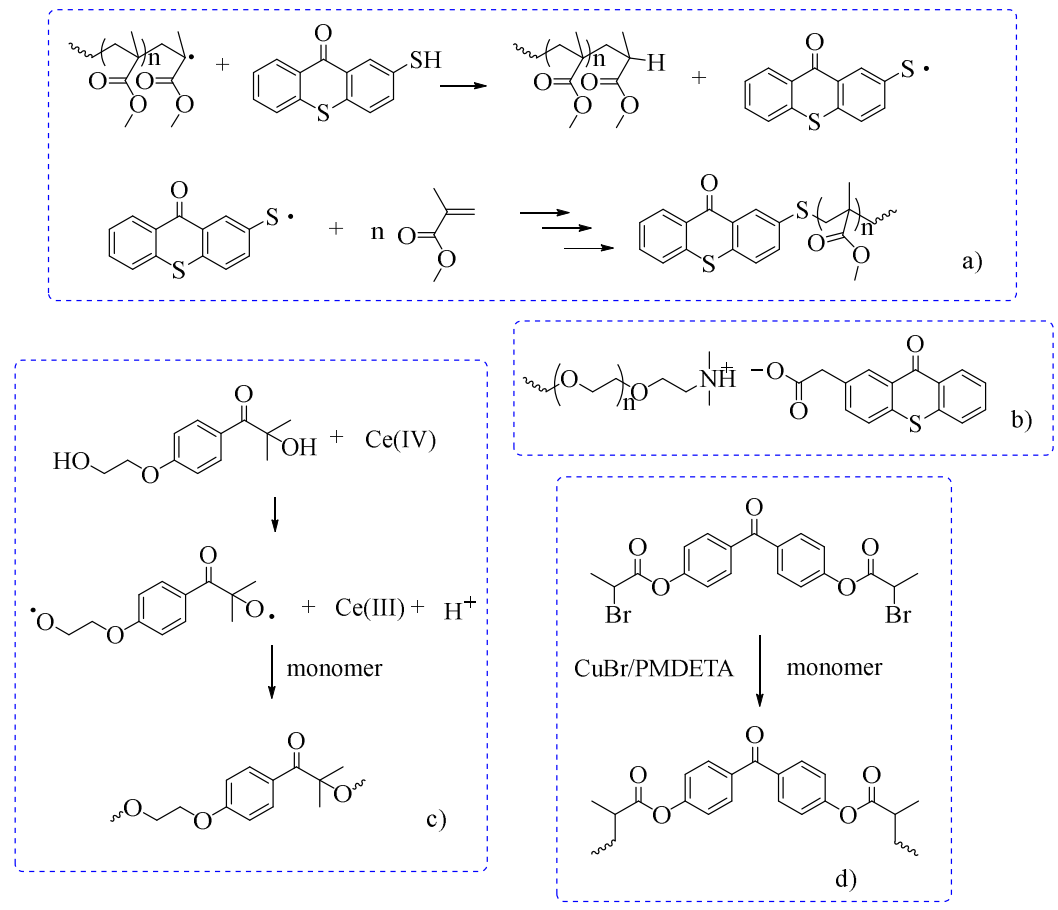

Scheme 7. Exemplary structures of LPPIs. 
Linear polymers bearing photosensitive conjugated groups in the backbone consequentially have property differences, both with respect to photodynamic and in thermodynamic properties, to common polymers. Jiang and Yin synthesized a PPI containing in-chain TX and coinitiator amines, which had a red-shifted maximum absorption (from $396 \mathrm{~nm}$ to $399 \mathrm{~nm}$ ) and a weaker fluorescent (Scheme 8a) compared to the corresponding TX model compounds (M1) [86]. They also modified that PPI with acrylate and styryl as the side groups, resulting blue shifts of absorption peaks (from $399 \mathrm{~nm}$ to $395 \mathrm{~nm}$ ) [87]. Wei et al. [57] also reported a similar result (M2). Ye et al. [64] designed an oligomeric photoinitiator containing $\alpha$-aminoalkylphenone chromophore (M1), which was found to have great thermal stability with a decomposition temperature higher than $300^{\circ} \mathrm{C}$ (Scheme 8c). The photoinitiating behavior of the oligo( $\alpha$-aminoketones) was also investigated (M1) [65]. Similarly, Wen et al. [97] synthesized several polymeric Michler's ketone photoinitiators (M1), demonstrating that the chain flexibility of LPPIs influences the photoinitiation efficiency (Scheme 8d). The difference in photoinitiation performance between LPPIs and their low-molecular-weight counterparts could be even greater, according to the work of Wei et al. (M2) [58]. They found that the LPPI they prepared had high photoefficiency $\left(\mathrm{R}_{\mathrm{p}, \max }=2.733 \times 10^{2} \mathrm{~s}^{-1}\right.$ and $\left.2.085 \times 10^{2} \mathrm{~s}^{-1}\right)$, while its counterpart, 4-amino-4'-[4-amino-thiophenyl]benzophenone, could hardly initiate the photopolymerization. 


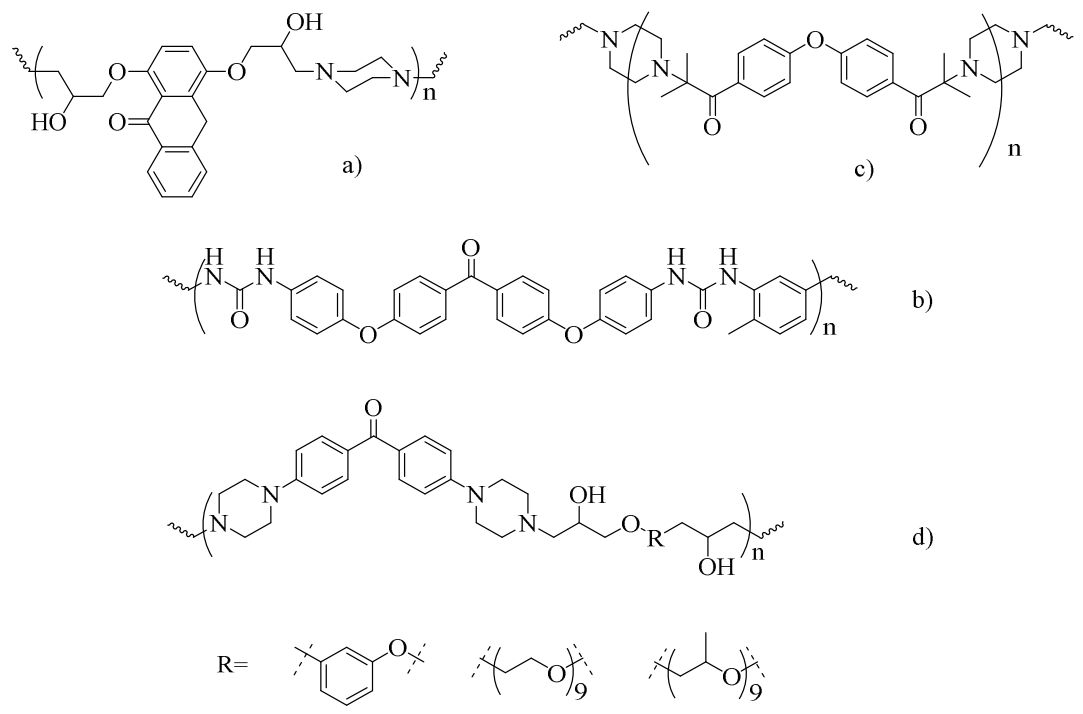

Scheme 8. Some of the LPPIs synthesized via step-growth polymerization.

The organic photoinitiators have been endowed with extraordinary properties by being located to polymer backbone. Suffering from their hydrophobicity, most organic radical photoinitiators are inapplicable to waterborne systems, which is the trend of UV-curing material development fulfilling the requirement of decreasing VOC. However, amphiphilic polymers provides one way to reach that goal (Scheme 9a-c). Thioxanthone had been introduced to water-soluble polymer (M1) [89] and amphiphilic block copolymer (M1) [90]. Wang et al. (M1) [33] utilized epoxy-modified BP as the end-capping agent in the polymerization of poly(ethylene glycol) (PEG), which is the typical representative of hydrophilic polymers, to obtain a series of one-component Type-II amphiphilic LPPIs. Wen et al. (M1) [100] found that the Michler's ketone LPPIs had different maximum absorption in $\mathrm{CH}_{2} \mathrm{Cl}_{2}$ and $\mathrm{H}_{2} \mathrm{O}$. Other researchers have discovered more exciting application of in-chain LPPIs. Polymeric gradient materials have attracted much attention in recent years. Gradient distribution of photoinitiators is a promising solution for overcoming the $\mathrm{O}_{2}$ inhibition of $\mathrm{UV}$-curing process. Polysiloxane has been chosen to be the backbone of "self-floating" LPPIs (M1) [28,31]. Zhang and co-workers (M1) [29] 
investigated the floating ability and photoinitiation kinetics of polysiloxane BP LPPIs with different silicone chain lengths. They also found that this polysiloxane LPPI has good control of wrinkling on UV-cured films (Scheme 9d). Seok et al. (M1) [17] introduced an acetophenone functionalized oligomeric LPPI to the preparation of polymer-dispersed liquid crystal film, which exhibited both driving voltage and high contrast ratio (Scheme 9e). Jiang et al. [96] synthesized a novel negative photosensitive polyimide with good photolithographic properties via polyimidization, the synthesis of which implied a new idea of coupling conjunction structures with PI groups.
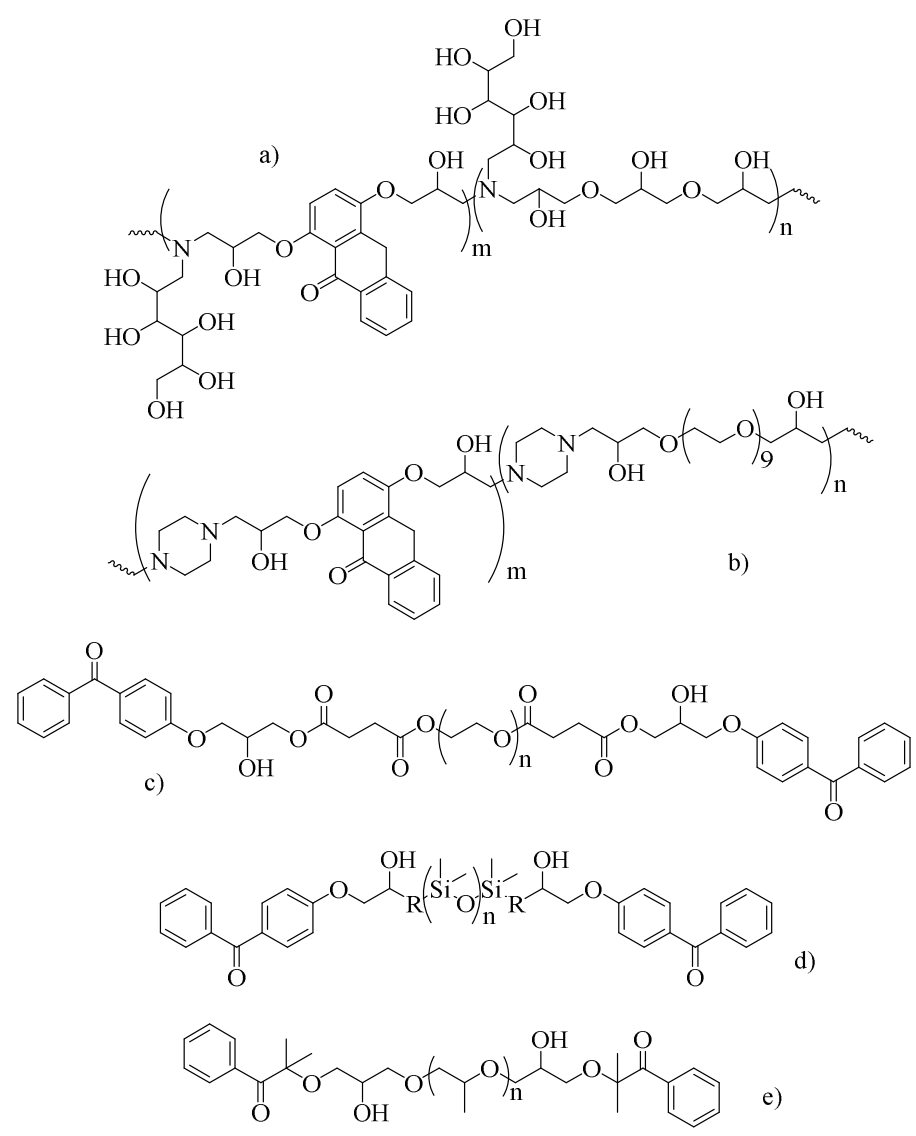

Scheme 9. LPPIs with additional properties: amphiphilic (a-c), self-floating (d) and matrix forming in liquid crystal (e).

\subsection{Side-chain LPPIs}

Moving the chromophores to the side-chain of polymers reduces the difficulty of preparing 
LPPIs. Some reactive groups such as acrylate [62-63,70,104], styrene [84] and epoxy (M1) [27,71], can be grafted to varied low-molecular-weight PIs or photosensitive conjugated molecules leading to "polymerizable photoinitiators" (Scheme 10). By means of either thermal polymerization [105] or more advanced synthetic techniques such as ATRP [72], researchers can fabricate side-chain LPPIs with ordinary backbones. Most of the work described in this chapter employed these methods. Nonetheless, modification of functionalized polymers is another facile and interesting route. Castelvetro et al. [85] performed phosphorylation of benzoic acid side-chain-functionalized polymer, to synthesize LPPI with acyl phosphine oxide PI, on the side chain. Durmaz and co-workers [103] introduced phenyl pyridinium ions into poly(styrene-co-chloromethylstyrene) with $\mathrm{AgSbF}_{6}$, followed by photo-induced grafting polymerization of MMA. The research groups of Arsu and Yagci grafted anthracene-thioxanthone [105] and BP [24] to the side chain of polystyrene via click reactions. Gomurashvili and Crivello [109] employed both homopolymerization of PI monomers and modification of polymer to prepare varied side-chain LPPIs.

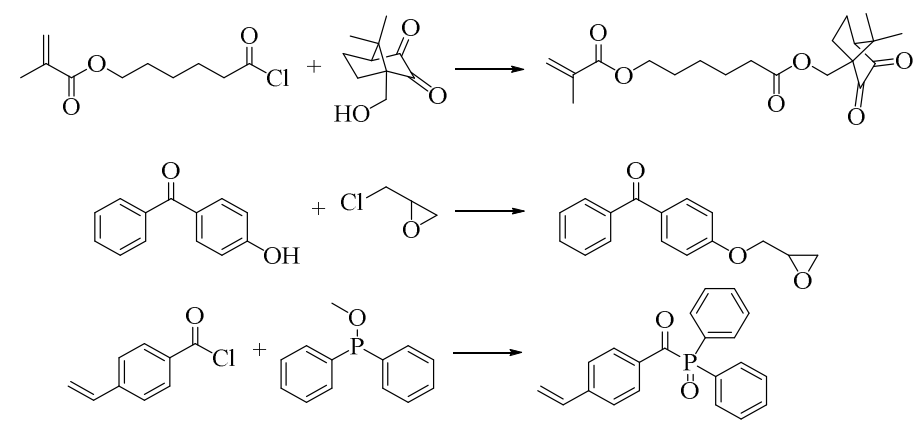

Scheme 10. Examples of "polymerizable photoinitiators".

Since the structural feature of side-chain LPPIs facilitates the synthesis of them, many research interests focus on the photochemical properties. Similar with the phenomenon described above, red shifts of the absorption were also observed in BP side-chain modified homopolymer 
(from $252 \mathrm{~nm}$ to 289 and $294 \mathrm{~nm}$ ) [35] and copolymer (from $267 \mathrm{~nm}$ to $289 \mathrm{~nm}$ ) [32]. Cesur et al. [53] found that the BP based side-chain LPPIs they synthesized were particularly efficient compared to BP (Scheme 11a). Taking advantage of the laser flash photolysis (LFP) system, Allonas et al. [62] reported the excited-states properties and photoreactivity of PMMA with camphorquinone (CQ) in the side chain (Scheme 11c). Another series of PMMA based side-chain LPPIs bearing BP derivatives were found to have different quantum yields in different solvents in Encinas's group [23] (Scheme 11b). When Wang et al. [107] bonded phenyl sulfide to BP in the side-chain of a polymer and investigated its photoinitiation behavior, they found that the BP derivative, known as a typical hydrogen-abstracting chromophore (Type-II PI), underwent C-S bond cleavage as a photofragmenting chromophore (Type-I PI), and initiated polymerization in the absence of any hydrogen donor (Scheme 11d). Moreover, this LPPI can also perform hydrogen abstraction in the presence of hydrogen donor. A study of one-component thioxanthone-based side-chain LPPIs came more recently. Avci et al. [76] have employed both thioxanthone groups and hydrogen donors on the side-chain of polymer via copolymerization. The solubility and photoinitiating activity of the LPPIs have been characterized.
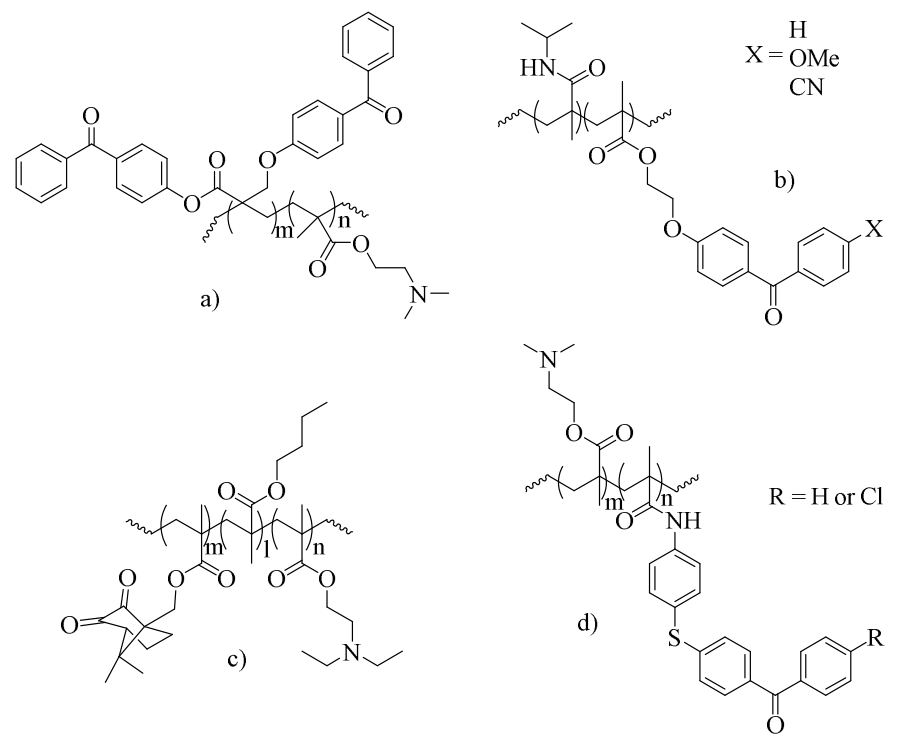
Scheme 11. Example LPPIs for which the kinetic of photoinitiation had been studied.

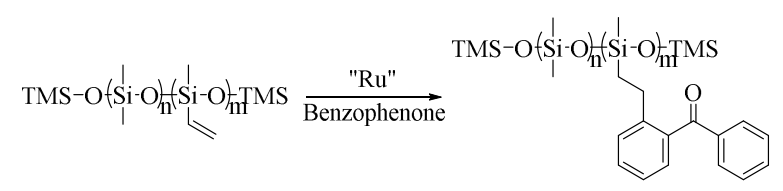

Scheme 12. Ru-catalyzed anti-Markovnikov addition of vinyl-substituted polysiloxane with benzophenone. [66], Copyright 2004. Reproduced with permission from John Wiley \& Sons Inc.

Most applications of side-chain LPPIs are similar to the in-chain ones, among which the application in hydrophile system has been the popular aspect so far $[74,84,102,104]$. Seok et al. [18] also developed a side-chain LPPI for liquid crystal film. Nevertheless, there had been several particular applications, which make side-chain LPPIs worth being discussed independently. Mabry and Weber [66] synthesized benzophenone-modified and anthracene-modified polysiloxanes by using Ru-catalyzed addition of an ortho $\mathrm{C}-\mathrm{H}$ bond of the two Type-II PIs across the C-C double bonds of vinyl-substituted siloxanes (Scheme 12). Those PI groups on the side-chain underwent crosslink reaction when heated to $300{ }^{\circ} \mathrm{C}$. Lee et al. [112] reported a systematic investigation of a series of photoreducible side-chain LPPIs for use in polymerization-based amplifications (Scheme 13). They coupled neutravidin, a deglycosylated product of native avidin from egg whites, to the LPPIs by dehydration condensation between carboxyl side group and amino functional compounds. This was used to recognize biotin-labeled DNA immobilized on glass chip surface and found that the number of PIs on macroinitiator had a great effect on the signal strength. Buller et al. [30] prepared a set of photo-crosslinkable copolymers based on oligo(ethylene glycol) methacrylate bearing 2-(4-benzoylphenoxy)ethyl methacrylate as a photosensitive crosslinking unit. Subsequent UV irradiation of spin-coated films onto silicon substrates led to biocompatible polymer films with broadened swelling-deswelling transition without hysteresis, which indicates the potential application in the 
bio-medical field.

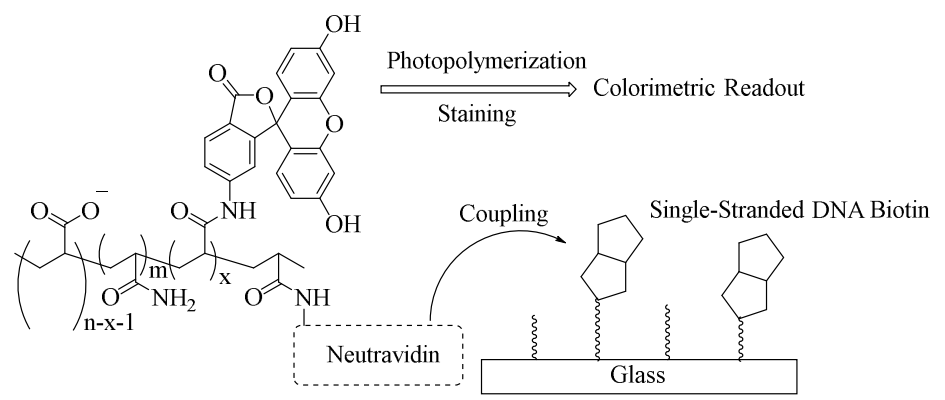

Scheme 13. LPPI used as signal amplifier in colorimetric bioassays. [112], Copyright 2012. Reproduced with permission from American Chemical Society.

\section{Hyperbranched and Cross-linked Polymeric Photoinitiators (HCPPIs)}

In recent decades, hyperbranched polymers have attracted much research interest due to their peculiar properties such as low viscosity and good solubility. Generally, hyperbranched polymer bearing photoinitiator groups is prepared via grafting routes, which can also be employed in cross-linked network. Therefore, it would be logical to discuss hyperbranched PPIs and cross-linked PPIs together. The irregularity of molecular structure and the incomputable functionality are common characteristics.

As a popular substrate for this kind of PPI, hyperbranched polymers can be modified with PIs on the terminal groups readily. Hyperbranched polyglycerol [36-37] and poly(ethylene imine) [77] had been employed as the cores and grafted by Type-II PIs mainly through M1 and esterification. What attracted more interest is the special structure of the cores. Si et al. [20] synthesized poly(siloxysilane) with $\mathrm{Si}-\mathrm{H}$ terminal groups and a series of acrylate-modified PIs. These two moieties were coupled via hydrosilylation of the hyperbranched organosilane (Scheme 14). 

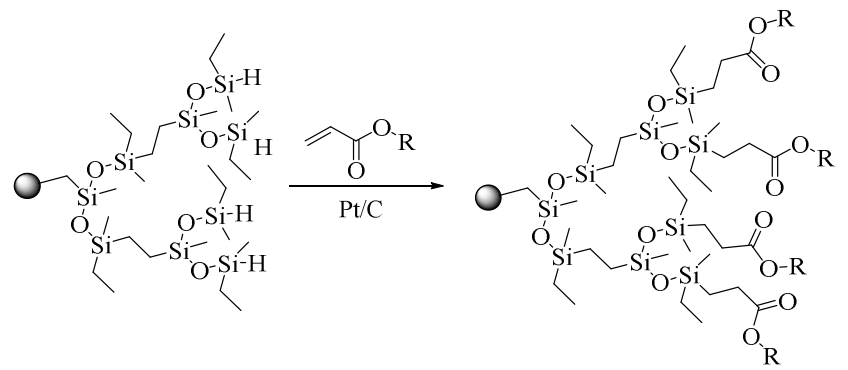

Scheme 14. Illustration of the hydrosilylation of hyperbranched organosilane.

A red-shifted UV absorption in the HCPPI products was observed due to the introduction of alkyl. Xie et al. [40] designed an $\mathrm{A}_{2} \mathrm{~B}_{3}$ monomer system for the synthesis of hyperbranched polymer, which contains hydrogen donor for the Type-II PIs located on the terminal groups. Moreover, a commercial hyperbranched polymer, which consists of hyperbranched polyester and polyether, was adopted by Shi and coworkers [38-39]. The UV-vis spectra of these research show an obvious red shift of $\pi-\pi^{*}$ absorption from $\sim 250 \mathrm{~nm}$ of BP to $\sim 280 \mathrm{~nm}$ of PPI.

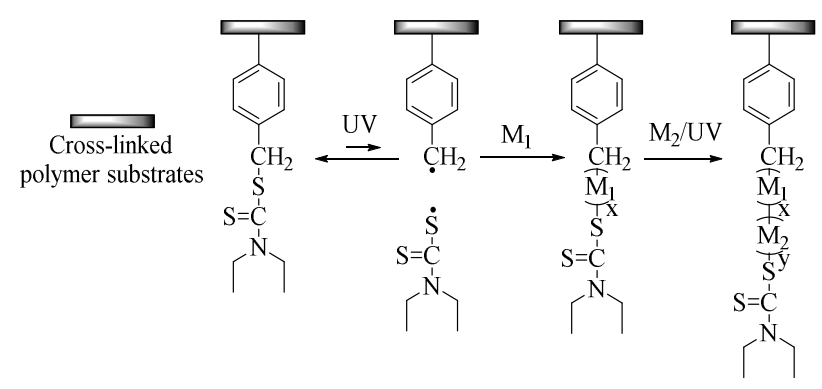

Scheme 15. Cross-linked polymer networks bearing dithiocarbamate photoiniferter. [67], Copyright 2002.

There are more choices for the core substrate to be grafted by the PIs. Luo et al. [67] synthesized a monomer photoiniferter bearing acrylate and dithiocarbamate. In the present of this monomer photoiniferter, a mixture of acrylate monomers was polymerized under UV irradiation to form polymer network, where the dormant species of the photoiniferter persisted (Scheme 15). Satoh et al. [110] reported another interesting instance. They immobilized eosin moieties on a 
nanosized silica surface, followed by photografting of various vinyl monomers under visible light at room temperature in the present of a reducing agent and oxygen (Scheme 16). The wettability of polymer-grafted silica surface, determined by the penetrating rate of water, was also discussed.

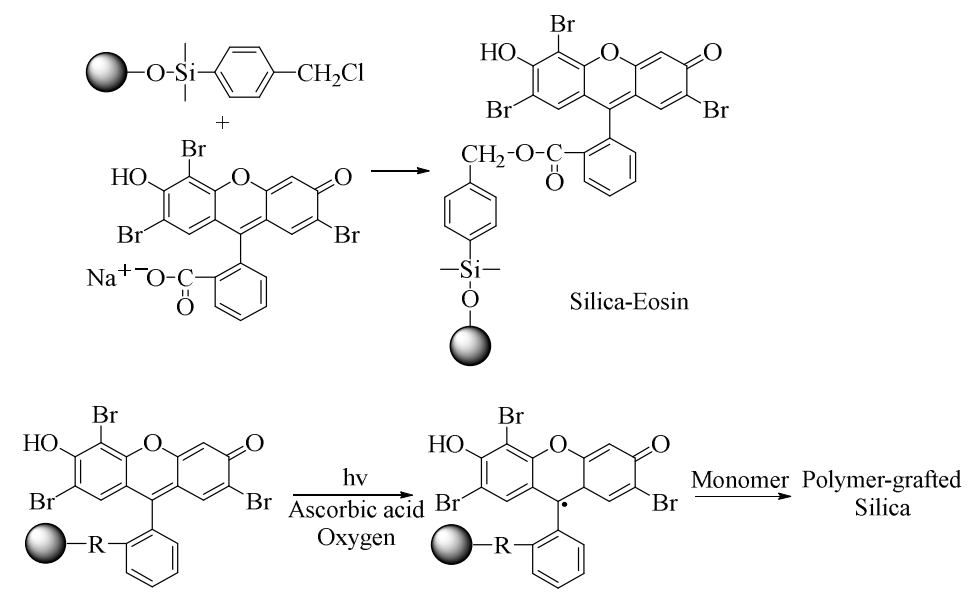

Scheme 16. Synthesis and photoinitiation of silica-eosin. [110], Copyright 2005. Reproduced with permission from John Wiley \& Sons Inc.

Recently, hyperbranched poly(ether amine) has been used as novel backbone for one-component polymeric type II photoinitiators [78]. By introducing thioxanthone (TX) or benzophenone (BP) moieties into the periphery of the hyperbranched polymer comprising the hydrophilic PEO short chain and coinitiator amine moieties in the backbone (Scheme 17). Due to its flexible, amphiphilic and hyperbranched structure, the synthesized HPIs could be dissolved very well not only in many organic systems including acrylate monomers, but also in water with high solubility of $10 \mathrm{wt} \%$. 

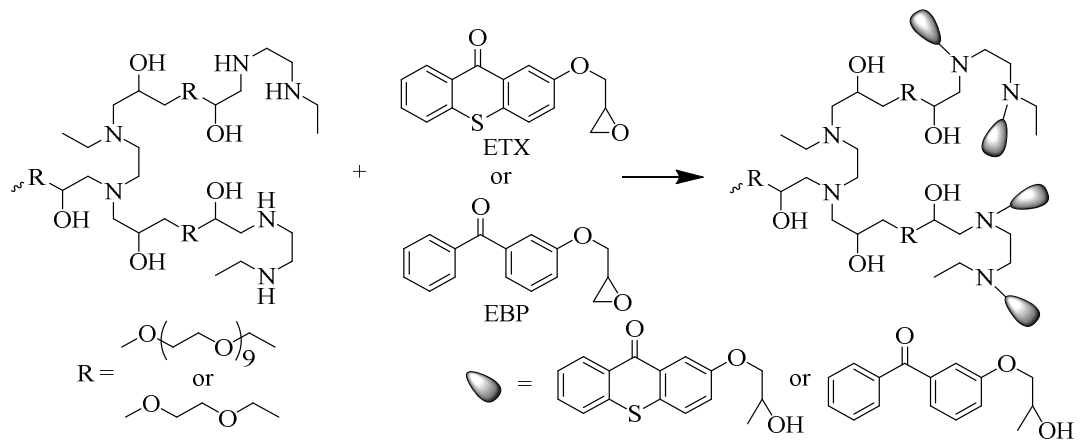

Scheme 17. Synthesis of one-component water-soluble hyperbranched poly(ether amine) containing thioxanthone or benzophenone photoinitiators.

\section{Multifunctional Photoinitiators (MFPIs)}

Among the varied kinds of PIs with high molecular weight, multifunctional photoinitiators MFPIs, which have defined number of functional groups, have been the Cinderella of industry due to the difficulty of remaining structural homogeneous in mass production. In order to prepare MFPI with high degree of functionality, dendrimer has been utilized as the core moiety. Even though the methodology of synthesizing MFPIs is similar to those of synthesizing hyperbranched PPIs, the structural regularity and the countability of functionality of MFPIs make them distinctive.

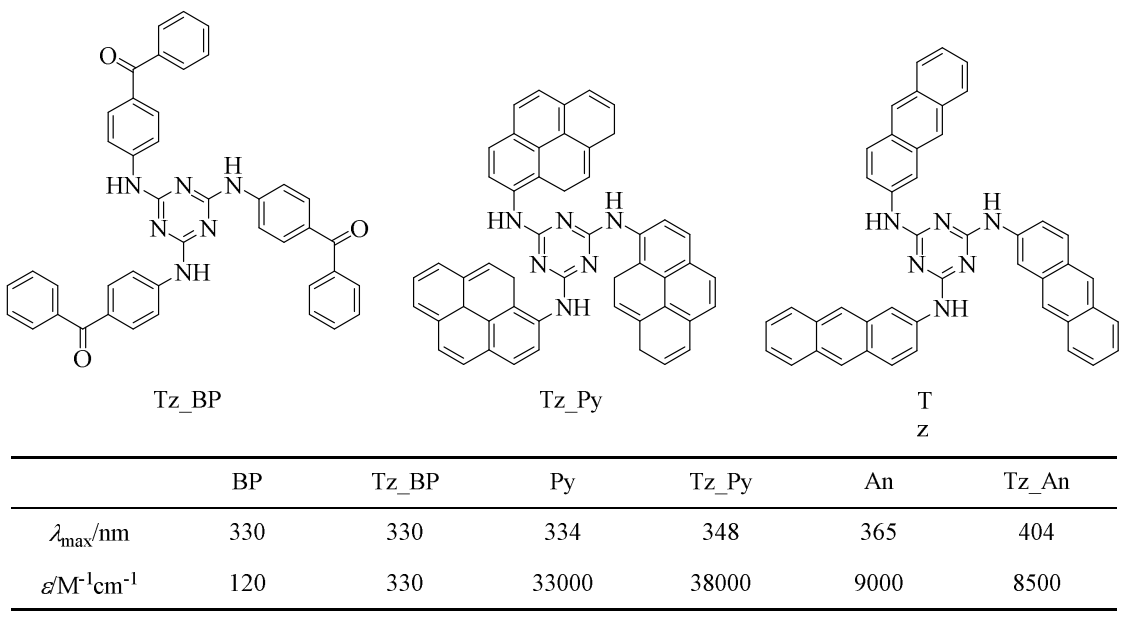

Figure 3. Trifunctional photoinitiators based on a triazine skeleton and their photochemical properties 
compared with benzophenone (BP), pyrene (Py) and anthracene (An) respectively. [41], Copyright 2012. Reproduced with permission from the American Chemical Society.

Simple molecular bis-/tri-functional PIs are, to an extent, expedients for industrial demand for low migration due to their synthetic facilitation. Ye et al. [54] prepared a novel difunctional PI, which can be regarded as two commercial PIs 2-hydroxy-2-methyl-1-phenyl-propanone (HMPP) strapped by an ether group. The synthesis process they employed was Friedel-Crafts acylation between phenyl and acyl chloride, which was similar to the manufacturing of HMPP but engendering a difunctional product. Allonas and coworkers [55] studied more bis-functional HMPP-based PIs with different linking bond, and investigated their excited-state processes. Difunctional compounds such as toluene-2,4-diisocyanate (TDI) [42] and acryl chlorides [43] were also adopted as the coupling agents of PIs. Tehfe et al. [41] synthesized three tri-functional Type-II PIs, which had large conjugate structures (Figure 3). Their light absorption properties were significantly improved by the strong molecular orbital coupling. Different light sources have been employed, such as Xe-Hg lamp (UV-visible light), halogen lamp (mostly visible light) and LED lamp (365 nm), to investigate their photoinitiation behavior. Luo et al. [83] presented a "green" idea that epoxidized soybean oil could be used as the promising intermediate for preparing MFPIs (Scheme 18). 


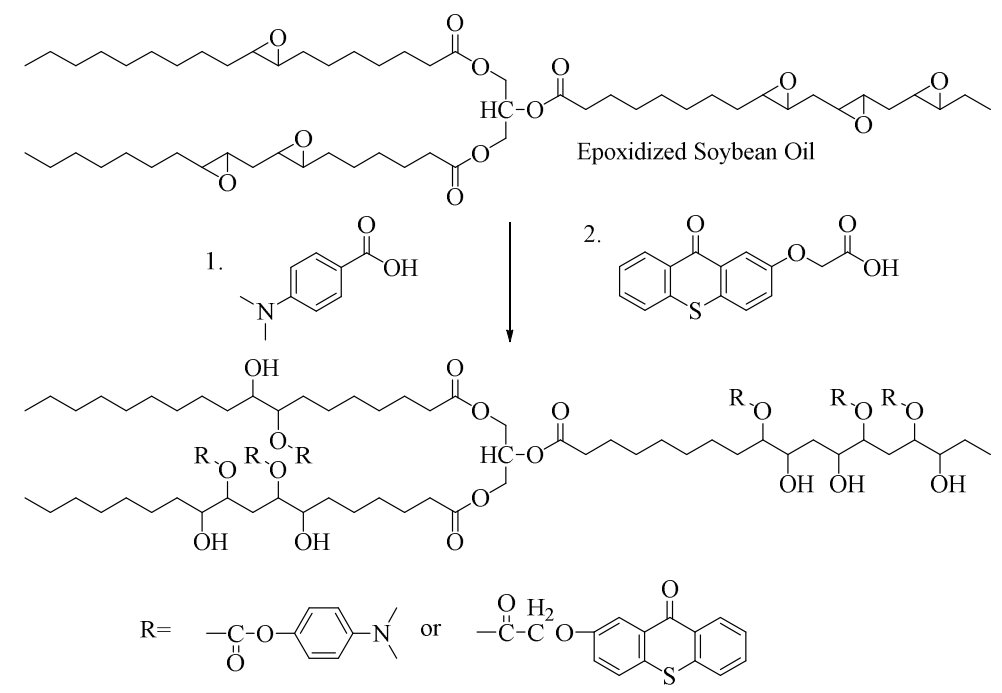

Scheme 18. Illustration of the grafting of epoxidized soybean oil with type-II photoinitiators and coinitiators. [83], Copyright 2012. Reproduced with permission from 'Elsevier Science Ltd.

As the functionality increases, the PIs in this family become more and more alike to dendritic polymer. Grafting PIs to an existing dendrimer have been a favored technique to some researchers [21]. Jiang and coworkers had been working on introducing thioxanthones to dendrimer poly(propylene imine)s, the products from which had interesting properties, containing hydrogen donors [79-80] and being water-compatible [81]. Kaastrup and Sikes [111] chose poly(amidoamine) dendrimers functionalized with eosins as MFPIs applied for photopolymerization-based signal amplifiers. Nevertheless, the candidates of so-called "scaffolds" in MFPIs are not restricted to dendritic polymers. Hu and Shi [56] employed a hexafunctional acrylic compound "EM265" as the core of a new MFPI. After modification of a commercial PI (2-hydroxy-1-[4-(2-hydroxyethoxy) phenyl]-2-methyl propan-1-one) and the subsequence addition reactions, the MFPI containing both acetophenones and ethoxysilanes had been prepared, which could also be used as a sol-gel precursor (Scheme 19). Cyclodextrin has attracted strong interests of researchers for its application in food, pharmaceutical, chemical and agricultural industry. As a multifunctional compound with distinctive structure, cyclodextrin can be 
chemically attached to PIs, according to Balta et al. [82] They also investigated its photoinitiated properties in aqueous medium.

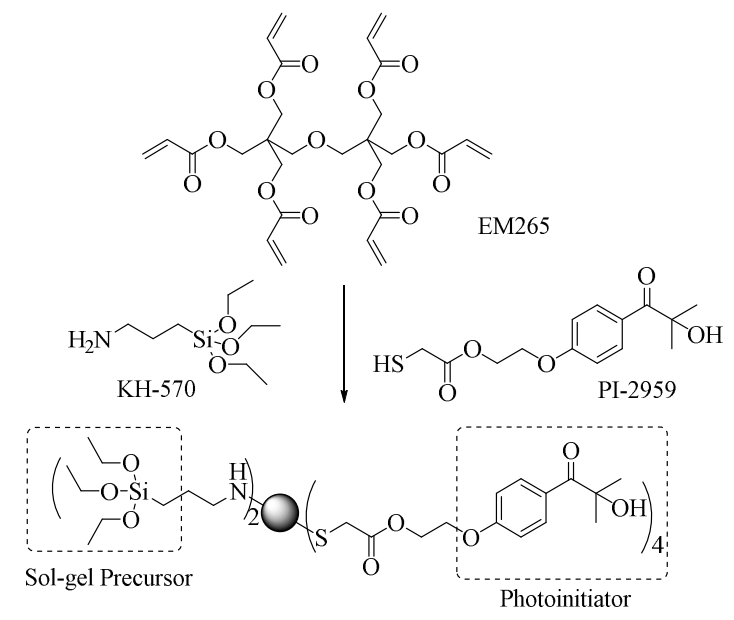

Scheme 19. Illustration of a multifunctional photoinitiator with sol-gel precursors.

Due to the synthesis difficulty and structural variety of HCPPIs and MFPIs, most of the research only demonstrated the ability of photoinitiation in common formulation under certain conditions. Nevertheless, more details on the properties of HCPPIs and MFPIs are required. In the report from Chen et al. [36], the extractability of the hyperbranched polyglycerol PPIs in UV-cured samples had been evaluated by HPLC. After the extraction of acetonitrile/ $\mathrm{H}_{2} \mathrm{O}$ solution of the samples with ultrasonic bath, the content of the residual BP and the coinitiator in the HCPPI samples were found much less than the samples with low-molecular-weight correspondent PI system.

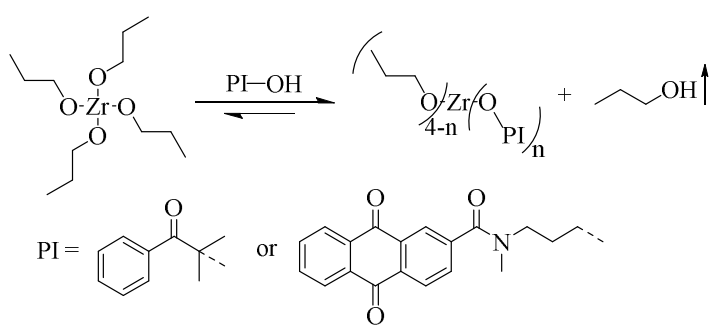

Scheme 20. Synthesis of type I and type II MFPIs via ligand substitution of organozirconium. 
Recently, a novel synthesis route for coupling photoinitiator groups to one MFPI was discovered by Zhou et al. The ligand groups on the organozirconiums can be substituted by other analogues under a mild condition, which can be a conventional PI [22] or its derivatives [44]. This kind of MFPIs can have good performance in migration and overcoming oxygen inhibition, while their photoinitiation activities have few advantages comparing to their low-molecular-weight analogues (Scheme 20).

\section{Migration testing for measuring UV photoinitiators}

In order to assess the migration potential of UV inks and coatings on food packaging prints, appropriate analytical methods are necessary in the packaging industry. Several groups of scientists have published their analytical methods for detecting UV-curable monomers and by-products with the migration potential into foods, since the late 1990s. Most of the studies reports migration tests on low molecular weight PIs. However, it is interesting to discuss the methodology and results reported in the literature as this could be easily adapted to PPIs or MFPIs.

As known, UV-curing formulations are complex mixtures and PIs are a very heterogeneous group of molecules with very diverse physicochemical properties, so analytical procedures need to be modified as a function of the molecule or group investigated. Moreover, different side-products can be generated by photocuring reactions under irradiation making the analysis even more complex.

An analytical method for detecting BP in carton board was extensively investigated by Anderson et al [116]. They developed GC-MS method using BP- $d_{10}$ as an internal standard to quantify BP, which might migrate from carton-board into foods. The limit of detection (LOD) was $0.01 \mathrm{mg} / \mathrm{kg}$ and the limit of quantification (LOQ) was $0.05 \mathrm{mg} / \mathrm{kg}$. BP was detected in the 
carton board samples $(0.01-7.3 \mathrm{mg} / \mathrm{kg})$ and the food samples $(0.01-5.7 \mathrm{mg} / \mathrm{kg})$. In addition, they calculated the mass fraction of BP migration for different temperatures (room temperature and chilled/frozen temperature) and different contacts (direct and indirect contact). They revealed interesting reduction effects of low temperature and indirect contact. They found that there was a six-fold reduction in migration for indirect contact compared with direct contact and a six-fold reduction for chilled/frozen storage compared with ambient storage and 40-fold reduction for the two contact conditions (indirect contact and chilled/frozen storage) combined. Based on these results, the authors concluded that $1-2 \%$ of the BP in the packaging migrated to the food. For foods where the BP levels were below the specific migration limit of $0.6 \mathrm{mg} / \mathrm{kg}$, levels in the corresponding packaging ranged from 5 to $7 \mathrm{mg} / \mathrm{kg}[116,117]$. Other studies have investigated levels of BP in the packaging of a variety of food products [118-121].

Emission of volatile organic compounds (VOCs) during UV curing processes and from UV-cured products would be of special concern in terms of indoor pollution. Salthammer et al. [122], investigated the VOCs produced during the photochemical process, for instance photoinitiators, their by-products and monomers, with a specially designed chamber including UV lamps and a purge-and-trap system. The collected VOCs were analyzed by GC-MS. The major VOCs found in their UV-curing processes were benzaldehyde, cyclohexanone and benzophenone. Unpolymerized acrylate monomers, TPGDA and HDDA were also detected from the chamber. It is worth noting that the odor issue was not scientifically addressed in the studies related to PPIs or MFPIs.

Johns et al [10], investigated migration of impregnated BP from carton board to foods during frozen storage $\left(-20^{\circ} \mathrm{C}\right)$ and then microwave heating using solvent extraction followed by GC-MS. BP was detected in some carton board samples suggesting the use of UV-cured inks with $\mathrm{BP}$ as the main PI. In addition to the $\mathrm{BP}$ migration study, migration of model ink 
components, which were impregnated in cardboards, was investigated. Among the model components, using more volatile substances showed higher migration rate than using fewer volatile substances. However, microwave heating of the food lowered migration levels of more volatile substances because of volatilization. Their study suggests that if the concentrations of low molecular weight volatiles are controlled by proper UV-curing process and if physical transfer of high molecular weight components via reverse side transfer phenomenon is taken care of, migration levels of printing ink components would be kept low in the frozen storage condition.

Castle et al. [123] investigated the migration of residues of dialkylamino benzophenone including Michler ketone (MK), 4,4' bis (dimethylamino) benzophenone, its analog, 4,4' bis (diethylamino) benzophenone (DEAB), and the monoamino form of MK, 4-(dimethylamino) benzophenone (DMAB), from paper and board food packaging materials. MK is not recommended for use in printing inks intended for carton board food packaging in the UK because MK is a potential carcinogen. However, in some other countries, MK is still being used. Their study was designed to assess the potential migration of MK, DEAB and DMAB in imported materials for food packaging. The samples, mainly printed carton boards, were extracted with ethanol, followed by the analysis of the extracts with HPLC and GC-MS. MK, DEAB and DMAB were detected from paper and board food contact materials. Also, MK was detected in imprinted materials. Their results suggest that the origin of the residues is from the use of recycled fibers. In addition, they analyzed some samples in which the highest concentration of MK was detected, but no measurable migration of MK at less than $2.0 \mathrm{pg} / \mathrm{kg}$ food was found.

In the literature, liquid chromatography (LC) and GC are the most commonly used techniques to analyze food and/or food contact materials. High-performance LC (HPLC)-based 
methods found in the literature have been summarized [6]. LC is the most elected technique due to the low volatility of PIs: when coupled to a diode array detector and/or fluorescence detection, it is the most extensively used for quantification purposes; when coupled to mass spectrometry, it can be used for confirmatory purposes or both identification and confirmation. However, LC-MS and LC-MS/MS are now commonly used to detect various substances. GC is very common for determining semi-volatile PIs such as BP and derivatives. Moreover, different detectors can be used, among which the MS detector is the most common [124].

\section{Perspectives and outlook}

UV-curing techniques play an important role because of their potential to facilitate environmental benign materials fabrication. A large amount of work has been done on the synthesis of low migration PIs as mentioned in this review, most of which was achieved in laboratory but not facile in industry. Among those methodologies and structures of low migration PIs, polymerizable photoinitiators can be the candidate to fulfill the expectations of low migration, facile synthesis and industrial applicability. With a slight modification on the formulation or the process, for instance, those polymerizable PIs mentioned in Scheme 10 can be used as both the PI and one of the monomers in UV-curing formulation. And the photochemistry products of them can be immobilized in the cured network, resulting in minimum migration. Furthermore, this immobility also works for leftover PI groups and most of the by-product fragments. Some intermediates of LPPIs described in previous chapters can be used to testify the immobility in cured product, since their efficiency of photoinitiation had been confirmed. One challenge that can be expected in molecular design is the reactivity of the monomer groups in polymerizable PIs, which is the critical factor in "fastening" PI groups (and their photochemistry products) in the cured network. Apart from employing monomer groups with high reactivity 
ratios to in the preparation of PIs, modifying the PIs with functional groups that reactive to acrylate, such as amino or thiol, can be logical methods to prepare polymerizable PIs.

\section{Acknowledgements}

ANR and Mäder are also fully acknowledged for financial support of the DeepCure project \#ANR-13-CHIN-0004-01. The authors thank the support from the National Natural Science Foundation of China (Grant No.: 51873043). 


\section{References}

[1] Schwalm R. UV coatings: basics, recent developments and new applications. Amsterdam: Elsevier Ltd, 2006. 322 pp.

[2] Dietliker K, Jung T, Benkhoff J, Kura H, Matsumoto A, Oka H, Hristova D, Gescheidt G, Rist G. New developments in photoinitiators. Macromol Symp 2004;217:77-97.

[3] Roffey, C. Photogeneration of Reactive Species for UV-curing. New York: Wiley, 1997. $1002 \mathrm{pp}$.

[4] Leach RH. Radiation curable systems. In: The Printing Manual 4th edition, Van Nostrand Reinhold London: Chapman \& Hall, 1988. p. 514-61.

[5] Allonas X, Croutxé-Barghorn C, Bögl KW, Helle N, Schreiber GA. Radiation Chemistry. In: Ullmann's Encyclopedia of Industrial Chemistry. Weinheim: Wiley-VCH Verlag GmbH, 2012. 34 pp. DOI: 10.1002/14356007.a22_471.pub2.

[6] Lago MA, Rodríguez-Bernaldo de Quirós A, Sendón R, Bustos J, Nieto MT, Paseiro P. Photoinitiators: a food safety review. Food Addit Contam Part A 2015;32:779-98.

[7] Snedeker SM. Benzophenone UV-photoinitiators used in food packaging: potential for human exposure and health risk considerations. In: Snedeker SM, editor. Toxicants in food packaging and household plastics. London: Springer Verlag, 2014. p. 151-76.

[8] Aparicio J. L., Elizalde, M., Migration of Photoinitiators in Food Packaging: A Review. Packag Techn Sci 2015;28:181-203.

[9] Anderson W, Castle L. Benzophenone in cartonboard packaging materials and the factors that influence its migration into food. Food Addit Contam 2003;20:607-18.

[10] Johns SM, Jickells SM, Read WA, Castle L. Studies on functional barriers to migration. 3. Migration of benzophenone and model ink components from cartonboard to food during frozen storage and microwave heating. Packag Techn Sci 2000;13:99-104.

[11] Rodríguez-Bernaldo de Quirós A, Paseiro-Cerrato R, Pastorelli S, Koivikko R, Simoneau C, Paseiro-Losada P. Migration of photoinitiators by gas phase into dry foods. J Agricul Food Chem 2009;57:10211-5.

[12] Jickells SM, Poulin J, Mountfort K, Fernandez-Ocana M. Migration of contaminants by gas phase transfer from carton board and corrugated board box secondary packaging into 
foods. Food Addit Contam 2005;22:768-82.

[13] Corrales T, Catalina F, Peinado C, Allen N. Free radical macrophotoinitiators: an overview on recent advances. J Photochem Photobiol A Chem 2003;159:103-14.

[14] Degirmenci M, Cianga I, Hizal G, Yagci Y. Synthesis, characterization and application of polymeric photoinitiators prepared by atom transfer radical polymerization and ring-opening polymerization. Polym Prepr ACS Polym Div 2002;43(2):22-3.

[15] Degirmenci M, Cianga I, Yagci Y. Synthesis of well-defined polystyrene macrophotoinitiators by atom-transfer radical polymerization. Macromol Chem Phys 2002;203:1279-84.

[16] Degirmenci M, Hizal G, Yagci Y. Synthesis and characterization of macrophotoinitiators of poly ( $\varepsilon$-caprolactone) and their use in block copolymerization. Macromolecules 2002;35:8265-70.

[17] Seok J, Ryu H, Seo H, Kim W, Lee D, Min K, Seo K, Kang I, Park L. Effect of oligomeric photoinitiator on the preparation and electro-optical property of polymer-dispersed liquid crystal. Opt Mater 2003;21:633-6.

[18] Seok JW, Han YS, Kwon Y, Park LS. Structural effect of photoinitiators on electro-optical properties of polymer - dispersed liquid crystal composite films. J Appl Polym Sci 2006;99:162-9.

[19] Degirmenci M, Urun T, Durgun M, Barim E. Synthesis of mid-chain functional macrophotoinitiators of poly(D,L-lactide) homopolymer and tetrablock poly(D,L-lactide)-poly( $\varepsilon$-caprolactone) copolymer by ring-opening polymerization. Des Monomers Polym 2015;18:669-77.

[20] Si QF, Fan XD, Liu YY, Kong J, Wang SJ, Qiao WQ. Synthesis and characterization of hyperbranched - poly (siloxysilane) - based polymeric photoinitiators. J Polym Sci Part A Polym Chem 2006;44:3261-70.

[21] Han W, Lin B, Zhou Y, Song J. Synthesis and properties of UV-curable hyperbranched polyurethane acrylate oligomers containing photoinitiator. Polym Bull 2012;68:729-43.

[22] Zhou J, Allonas X, Liu X. Zirconium Propoxide: A Coupling Agent for the Synthesis of Multifunctional Photoinitiators. ChemPhotoChem 2018;2:18-21.

[23] Rufs A, Valdebenito A, Rezende M, Bertolotti S, Previtali C, Encinas M. Synthesis and photoinitiation activity of macroinitiators comprising benzophenone derivatives. Polymer 
2008;49:3671-6.

[24] Temel G, Aydogan B, Arsu N, Yagci Y. Synthesis and characterization of one-component polymeric photoinitiator by simultaneous double click reactions and its use in photoinduced free radical polymerization. Macromolecules 2009;42:6098-106.

[25] Temel G, Aydogan B, Arsu N, Yagci Y. Synthesis of block and star copolymers by photoinduced radical coupling process. J Polym Sci Part A Polym Chem 2009;47:2938-47.

[26] Wei J, Lu R, Liu F. Novel, highly efficient polymeric benzophenone photoinitiator containing coinitiator moieties for photopolymerization. Polym Adv Technol 2010;21:656-62.

[27] Cheng L, Shi W. Synthesis and photoinitiating behavior of benzophenone-based polymeric photoinitiators used for UV curing coatings. Prog Org Coat 2011;71:355-61.

[28] Sun F, Zhang N, Nie J, Du H. Control of concentration gradient and initiating gradient photopolymerization of polysiloxane benzophenone photoinitiator. J Mater Chem 2011;21:17290-6.

[29] Zhang N, Li M, Nie J, Sun F. Microstructure and surface property of macroscopic gradient polymer initiated by polysiloxane benzophenone photoinitiators with different silicone chain lengths. J Mater Chem 2012;22:9166-72.

[30] Buller J, Laschewsky A, Wischerhoff E. Photoreactive oligoethylene glycol polymersversatile compounds for surface modification by thin hydrogel films. Soft Matter 2013;9:929-37.

[31] Wang J, Cheng J, Liu J, Gao Y, Sun F. Self-floating ability and initiating gradient photopolymerization of acrylamide aqueous solution of a water-soluble polysiloxane benzophenone photoinitiator. Green Chem 2013;15:2457-65.

[32] Karahan Ö, Balta DK, Arsu N, Avci D. Synthesis and evaluations of novel photoinitiators with side-chain benzophenone, derived from alkyl $\alpha$-hydroxymethacrylates. J Photochem Photobiol A Chem 2014;274:43-9.

[33] Wang K, Lu Y, Chen P, Shi J, Wang H, Yu Q. Novel one-component polymeric benzophenone photoinitiator containing poly (ethylene glycol) as hydrogen donor. Mater Chem Phys 2014;143:1391-5.

[34] Wang K, Yang K, Yu Q. Novel polymeric photoinitiators with side-chain benzophenone: 
Facile synthesis and photopolymerization properties without coinitiator. Prog Org Coat 2014;77:1929-34.

[35] Balta DK, Karahan Ö, Avci D, Arsu N. Synthesis, photophysical and photochemical studies of benzophenone based novel monomeric and polymeric photoinitiators. Prog Org Coat 2015;78:200-7.

[36] Chen Y, Loccufier J, Vanmaele L, Barriau E, Frey H. Novel multifunctional polymeric photoinitiators and photo-coinitiators derived from hyperbranched polyglycerol. Macromol Chem Phys 2007;208:1694-706.

[37] Chen Y, Loccufier J, Vanmaele L, Frey H. Novel multifunctional hyperbranched polymeric photoinitiators with built-in amine coinitiators for UV curing. J Mater Chem 2007;17:3389-92.

[38] Hu L, Asif A, Xie J, Shi W. Synthesis and photoinitiating behavior of hyperbranched polymeric photoinitiators bearing coinitiator amine. Polym Adv Technol 2011;22:1673-80.

[39] Xie H, Hu L, Zhang Y, Shi W. Sulfur-containing hyperbranched polymeric photoinitiator end-capped with benzophenone and tertiary amine moieties prepared via simultaneous double thiol-ene click reactions used for UV curing coatings. Prog Org Coat 2011;72:572-8.

[40] Xie H, Hu L, Shi W. Synthesis and photoinitiating activity study of polymeric photoinitiators bearing BP moiety based on hyperbranched poly (ester-amine) via thiolene click reaction. J Appl Polym Sci 2012;123:1494-501.

[41] Tehfe MA, Dumur F, Graff B, Morlet-Savary F, Fouassier JP, Gigmes D, Lalevée J. Trifunctional photoinitiators based on a triazine skeleton for visible light source and UV LED induced polymerizations. Macromolecules 2012;45:8639-47.

[42] Xiao P, Dai M, Nie J. Synthesis and photopolymerization characterization of a novel difunctional photoinitiator. J Appl Polym Sci 2008;108:665-70.

[43] Wang C, Wei L, Lai G, Zhong T, Shen Y. Synthesis and photopolymerization kinetics of lower odor benzophenone derivative photoinitiators. Polym Adv Technol 2010;21:72-6.

[44] Zhou J, Allonas X, Liu X. Synthesis and characterization of organozirconiums with type-II photoinitiator ligands as multifunctional photoinitiators for free radical photopolymerization. J Photochem Photobiol A Chem 2018;356:580-6. 
[45] Degirmenci M, Genli N. Synthesis of Well-Defined telechelic macrophotoinitiator of polystyrene by combination of atrp and click chemistry. Macromol Chem Phys 2009;210:1617-23.

[46] Wei J, Wang H, Jiang X, Yin J. Effect on photopolymerization of the structure of amine coinitiators contained in novel polymeric benzophenone photoinitiators. Macromol Chem Phys 2006;207:1752-63.

[47] Wei J, Jiang XS, Wang HY. Effect of the Structure of Photosensitive Groups Contained in Novel PU-Type Polymeric Benzophenone Photoinitiators on Photopolymerization. Macromol Chem Phys 2007;208:2303-11.

[48] Wei J, Wang H, Jiang X, Yin J. Study of Novel PU-Type Polymeric Photoinitiators Comprising of Side-Chain Benzophenone and Coinitiator Amine: Effect of Macromolecular Structure on Photopolymerization. Macromol Chem Phys 2007;208:287-94.

[49] Wei J, Wang H, Jiang X, Yin J. Novel photosensitive thio-containing polyurethane as macrophotoinitiator comprising side-chain benzophenone and co-initiator amine for photopolymerization. Macromolecules 2007;40:2344-51.

[50] Degirmenci M, Akbulut MA, Hicri S, Yilmaz H. Synthesis and characterization of a novel mid-chain macrophotoinitiator of poly (methyl methacrylate) by Ce (IV)/HNO3 redox system. Polym J 2008;40:729-35.

[51] Degirmenci M, Hicri S, Yilmaz H. Synthesis and characterization of a novel water-soluble mid-chain macrophotoinitiator of polyacrylamide by Ce (IV)/HNO3 redox system. Eur Polym J 2008;44:3776-81.

[52] Degirmenci M, Taskesen E, Hicri S, Yilmaz H. Synthesis and characterization of a novel mid-chain macrophotoinitiator of polyacrylonitrile by $\mathrm{Ce}$ (IV)/HNO3 redox system. J Polym Sci Part A Polym Chem 2008;46:5404-13.

[53] Cesur B, Karahan O, Agopcan S, Eren TN, Okte N, Avci D. Difunctional monomeric and polymeric photoinitiators: synthesis and photoinitiating behaviors. Prog Org Coat 2015;86:71-8.

[54] Ye G, Ke Z, Yang J, Zhao T, Zeng Z, Chen Y. Low VOC bifunctional photoinitiator based on $\alpha$-hydroxyalkylphenone structure. Polymer 2006;47:4603-12.

[55] Dietlin C, Lalevee J, Allonas X, Fouassier JP, Visconti M, Bassi GL, Norcini G. 
Reactivity and efficiency of difunctional radical photoinitiators. J Appl Polym Sci 2008;107:246-52.

[56] Hu L, Shi W. UV-cured organic-inorganic hybrid nanocomposite initiated by trimethoxysilane-modified fragmental photoinitiator. Composites Part A 2011;42:631-8.

[57] Wei J, Wang H, Jiang X, Yin J. A highly efficient polyurethane-type polymeric photoinitiator containing in-chain benzophenone and coinitiator amine for photopolymerization of PU prepolymers. Macromol Chem Phys 2006;207:2321-8.

[58] Wei J, Wang H, Yin J. Novel polymeric, thio-containing photoinitiator comprising inchain benzophenone and an amine coinitiator for photopolymerization. J Polym Sci Part A Polym Chem 2007;45:576-87.

[59] Wei J, Lu R, Liu F. Effect of photosensitive groups on the photoefficiency of polymeric photoinitiators. J Polym Res 2011;18:1001-8.

[60] Degirmenci M. Synthesis of novel well-defined end-functional macrophotoinitiator of poly ( $\varepsilon$-caprolactone) by ring-opening polymerization. Polym J 2004;36:542-48.

[61] Degirmenci M. Synthesis and characterization of novel well-defined end-functional macrophotoinitiator of poly (MMA) by ATRP. J Macromol Sci A 2005;42:21-30.

[62] Allonas X, Fouassier JP, Angiolini L, Caretti D. Excited-state properties of camphorquinone based monomeric and polymeric photoinitiators. Helv Chim Acta $2001 ; 84: 2577-88$.

[63] Angiolini L, Caretti D, Rossetti S, Salatelli E, Scoponi M. Radical polymeric photoinitiators bearing side-chain camphorquinone moieties linked to the main chain through a flexible spacer. J Polym Sci Part A Polym Chem 2005;43:5879-88.

[64] Ye G, Zhou H, Yang J, Zeng Z, Chen Y. Synthesis and characterization of oligomers containing the $\alpha$-aminoalkylphenone chromophore as oligomeric photoinitiator. J Appl Polym Sci 2006;99:3417-24.

[65] Ye G, Zhou H, Yang J, Zeng Z, Chen Y. Photoinitiating behavior of macrophotoinitiator containing aminoalkylphenone group. J Therm Anal Calor 2006;85:771-7.

[66] Mabry JM, Weber WP. Synthesis and thermal crosslinking of benzophenone-modified poly (dimethylsiloxane) s. J Polym Sci Part A Polym Chem 2004;42:5514-22.

[67] Luo N, Hutchison JB, Anseth KS, Bowman CN. Synthesis of a novel methacrylic monomer iniferter and its application in surface photografting on crosslinked polymer 
substrates. J Polym Sci Part A Polym Chem 2002;40:1885-91.

[68] Wang Y, Jiang X, Yin J. Novel polymeric photoinitiators comprising of side-chain benzophenone and coinitiator amine: Photochemical and photopolymerization behaviors. Eur Polym J 2009;45:437-47.

[69] Cakmak I, Ozturk T. Synthesis of triblock copolymers via photopolymerization of styrene and methyl methacrylate using macrophotoinitiators possessing poly (ethylene glycol) units. J Polym Res 2005;12:121-6.

[70] Corrales T, Catalina F, Peinado C, Allen N, Rufs A, Bueno C, et al. Photochemical study and photoinitiation activity of macroinitiators based on thioxanthone. Polymer 2002;43:4591-7.

[71] Jiang X, Xu H, Yin J. Polymeric amine bearing side-chain thioxanthone as a novel photoinitiator for photopolymerization. Polymer 2004;45:133-40.

[72] Temel G, Arsu N, Yagci Y. Polymeric side chain thioxanthone photoinitiator for free radical polymerization. Polym Bull 2006;57:51-6.

[73] Karasu F, Arsu N, Yagci Y. 2-Mercapto thioxanthone as a chain transfer agent in freeradical polymerization: A versatile route to incorporate thioxanthone moieties into polymer chain-ends. J Appl Polym Sci 2007;103:3766-70.

[74] Temel G, Arsu N. One-pot synthesis of water-soluble polymeric photoinitiator via thioxanthonation and sulfonation process. J Photochem Photobiol A Chem 2009;202:63-6.

[75] Yilmaz G, Acik G, Yagci Y. Counteranion sensitization approach to photoinitiated free radical polymerization. Macromolecules 2012;45:2219-24.

[76] Eren TN, Okte N, Morlet-Savary F, Fouassier JP, Lalevee J, Avci D. One-component thioxanthone-based polymeric photoinitiators. J Polym Sci Part A Polym Chem 2016;54:3370-8.

[77] Wen Y, Jiang X, Liu R, Yin J. Amphipathic hyperbranched polymeric thioxanthone photoinitiators (AHPTXs): Synthesis, characterization and photoinitiated polymerization. Polymer 2009;50:3917-23.

[78] Li T, Su Z, Xu H, Jiang X, Ma X, Yin J. Hyperbranched poly(ether amine) (hPEA) as novel backbone for amphiphilic one-component type-II polymeric photoinitiators. Chin Chem Lett 2018;29:451-5.

[79] Jiang X, Yin J. Dendritic macrophotoinitiator containing thioxanthone and coinitiator 
amine. Macromolecules 2004;37:7850-3.

[80] Jiang X, Xu H, Yin J. Copolymeric dendritic macrophotoinitiators. Polymer 2005;46:11079-84.

[81] Jiang X, Wang W, Xu H, Yin J. Water-compatible dendritic macrophotoinitiator containing thioxanthone. J Photochem Photobiol A Chem 2006;181:233-7.

[82] Balta DK, Bagdatli E, Arsu N, Ocal N, Yagci Y. Chemical incorporation of thioxanthone into $\beta$-cyclodextrin and its use in aqueous photopolymerization of methyl methacrylate. $\mathrm{J}$ Photochem Photobiol A Chem 2008;196:33-7.

[83] Luo A, Jiang X, Yin J. Thioxanthone-containing renewable vegetable oil as photoinitiators. Polymer 2012;53:2183-9.

[84] de Groot JH, Dillingham K, Deuring H, Haitjema HJ, van Beijma FJ, Hodd K, Norrby S. Hydrophilic polymeric acylphospine oxide photoinitiators/crosslinkers for in vivo blue-light photopolymerization. Biomacromolecules 2001;2:1271-8.

[85] Castelvetro V, Molesti M, Rolla P. UV-curing of acrylic formulations by means of polymeric photoinitiators with the active 2, 6-dimethylbenzoylphosphine oxide moieties pendant from a tetramethylene side chain. Macromol Chem Phys 2002;203:1486-96.

[86] Jiang X, Yin J. Polymeric photoinitiator containing in-chain thioxanthone and coinitiator amines. Macromol Rapid Commun 2004;25:748-52.

[87] Jiang X, Yin J. Copolymeric photoinitiators containing in-chain thioxanthone and coinitiator amine for photopolymerization. J Appl Polym Sci 2004;94:2395-400.

[88] Jiang X, Yin J. Study of macrophotoinitiator containing in-chain thioxanthone and coinitiator amines. Polymer 2004;45:5057-63.

[89] Jiang X, Yin J. Water-soluble polymeric thioxanthone photoinitiator containing glucamine as coinitiator. Macromol Chem Phys 2008;209:1593-600.

[90] Jiang X, Luo J, Yin J. A novel amphipathic polymeric thioxanthone photoinitiator. Polymer 2009;50:37-41.

[91] Matsuura Y, Matsukawa K, Kawabata R, Higashi N, Niwa M, Inoue H. Synthesis of polysilane-acrylamide copolymers by photopolymerization and their application to polysilane-silica hybrid thin films. Polymer 2002;43:1549-53.

[92] Matsukawa K. Development of photo-functional materials from organic/inorganic nano-hybrids. J Photopolym Sci Technol 2005;18:203-10. 
[93] He L, Chen B, Iso M. A novel photobleachable polysilane copolymer for optical waveguide fabrication. Polym Adv Technol 2011;22:1056-9.

[94] Liang Q, Zhang L, Xiong Y, Wu Q, Tang H. A facile method to prepare a polyethylene glycol modified polysilane as a waterborne photoinitiator. J Photochem Photobiol A Chem 2015;299:9-17.

[95] Jiang X, Luo X, Yin J. Polymeric photoinitiators containing in-chain benzophenone and coinitiators amine: Effect of the structure of coinitiator amine on photopolymerization. $J$ Photochem Photobiol A Chem 2005;174:165-70.

[96] Jiang X, Li H, Wang H, Shi Z, Yin J. A novel negative photoinitiator-free photosensitive polyimide. Polymer 2006;47:2942-5.

[97] Wen Y, Jiang X, Yin J. Polymeric Michler's ketone photoinitiators: The effect of chain flexibility. Prog Org Coat 2009;66:65-72.

[98] Wen Y, Jiang X, Yin J. Polymeric Michler's ketone photoinitiator containing coinitiator amine. Polym Eng Sci 2009;49:1608-15.

[99] Temel G, Karaca N, Arsu N. Synthesis of main chain polymeric benzophenone photoinitiator via thiol-ene click chemistry and Its use in free radical polymerization. $\mathbf{J}$ Polym Sci Part A Polym Chem 2010;48:5306-12.

[100] Wen Y, Jiang X, Liu R, Yin J. Amphiphilic polymeric Michler's ketone (MK) photoinitiators (APMKs) containing PEO chain and coinitiator amine. Polym Adv Technol 2011;22:598-604.

[101] Tehfe MA, Lalevée J, Shankar R, Sahoo U, Morlet-Savary F, Graff B, et al. Branched and Network Polysilanes as Cleavable Macrophotoinitiators. Macromol Chem Phys 2011;212:2619-25.

[102] Catalina F, Peinado C, Blanco M, Corrales T, Allen N. Synthesis, photochemical and photoinitiation activity of water-soluble copolymers with anthraquinone chromophores as side-chain groups. Polymer 2001;42:1825-32.

[103] Durmaz YY, Yilmaz G, Yagci Y. Polymers with side chain n-alkoxy pyridinium ions as precursors for photoinduced grafting and modification processes. Macromol Chem Phys 2007;208:1737-43.

[104] Corrales T, Catalina F, Allen N, Peinado C. Novel water soluble copolymers based on thioxanthone: photochemistry and photoinitiation activity. J Photochem Photobiol A 
Chem 2005;169:95-100.

[105] Gacal B, Akat H, Balta DK, Arsu N, Yagci Y. Synthesis and characterization of polymeric thioxanthone photoinitatiors via double click reactions. Macromolecules 2008;41:2401-5.

[106] Akat H, Gacal B, Balta DK, Arsu N, Yagci Y. Poly (ethylene glycol)-thioxanthone prepared by Diels-Alder click chemistry as one-component polymeric photoinitiator for aqueous free-radical polymerization. J Polym Sci Part A Polym Chem 2010;48:2109-14.

[107] Wang H, Wei J, Jiang X, Yin J. Highly efficient sulfur-containing polymeric photoinitiators bearing side-chain benzophenone and coinitiator amine for photopolymerization. J Photochem Photobiol A Chem 2007;186:106-14.

[108] Wei J, Liu F. Novel highly efficient macrophotoinitiator comprising benzophenone, coinitiator amine, and thio moieties for photopolymerization. Macromolecules 2009;42:5486-91.

[109] Gomurashvili Z, Crivello JV. Monomeric and polymeric phenothiazine photosensitizers for photoinitiated cationic polymerization. Macromolecules 2002;35:2962-9.

[110] Satoh M, Shirai K, Saitoh H, Yamauchi T, Tsubokawa N. Photografting of polymers onto nanosized silica surface initiated by eosin moieties immobilized onto the surface. J Polym Sci Part A Polym Chem 2005;43:600-6.

[111] Kaastrup K, Sikes H. Investigation of dendrimers functionalized with eosin as macrophotoinitiators for polymerization-based signal amplification reactions. RSC Adv 2015;5:15652-9.

[112] Lee JK, Heimer BW, Sikes HD. Systematic study of fluorescein-functionalized macrophotoinitiators for colorimetric bioassays. Biomacromolecules 2012;13:1136-43.

[113] Matyjaszewski K. Atom transfer radical polymerization (ATRP): current status and future perspectives. Macromolecules 2012;45:4015-39.

[114] Vogt AP, Sumerlin BS. An efficient route to macromonomers via ATRP and click chemistry. Macromolecules 2006;39:5286-92.

[115] Laurent BA, Grayson SM. An efficient route to well-defined macrocyclic polymers via “click” cyclization. J Am Chem Soc 2006;128:4238-9.

[116] Anderson MJ, Whitcomb PJ. DOE simplified: practical tools for effective experimentation. Boca Raton: CRC Press, 2016. p. 1-68.

[117] Bugey A, Janin Y, Edder P, Bieri S. Targeted multidimensional gas chromatography using 
a heart-cutting device and cryogenic focusing for the determination of benzophenone derivatives in foodstuffs. Anal Bioanal Chem 2013;405:4177-85.

[118] Jung T, Simat T, Altkofer W, Fügel D. Survey on the occurrence of photo-initiators and amine synergists in cartonboard packaging on the German market and their migration into the packaged foodstuffs. Food Addit Contam Part A 2013;30:1993-2016.

[119] Ozaki A, Yamaguchi Y, Okamoto A, Kawai N. Determination of alkylphenols, bisphenol A, benzophenone and phthalates in containers of baby food, and migration into food simulants. J Food Hyg Soc Jpn 2002;43:260-6.

[120] Sanches-Silva A, Pastorelli S, Cruz J, Simoneau C, Castanheira I, Paseiro-Losada P. Development of an analytical method for the determination of photoinitiators used for food packaging materials with potential to migrate into milk. J Dairy Sci 2008;91:900-9.

[121] Shen D, Lian H, Ding T, Xu J, Shen C. Determination of low-level ink photoinitiator residues in packaged milk by solid-phase extraction and LC-ESI/MS/MS using triple-quadrupole mass analyzer. Anal Bioanal Chem 2009;395:2359-70.

[122] Salthammer T, Bednarek M, Fuhrmann F, Funaki R, Tanabe S. Formation of organic indoor air pollutants by UV-curing chemistry. J Photochem Photobiol A Chem 2002;152:1-9.

[123] Castle L, Damant AP, Honeybone CA, Jickells SM, Sharman M, Gilbert J. Migration studies from paper and board food packaging materials. Part 2. Survey for residues of dialkylamkto benzophenone UV-cure ink photoinitiators. Food Addit Contam 1997; 14:45-52.

[124] Lago M, de Quirós ARB, Sendón R, Bustos J, Santillana M, Paseiro P. Simultaneous chromatographic analysis of photoinitiators and amine synergists in food contact materials. Anal Bioanal Chem 2014;406:4251-9. 
Side-chain...

In-chain...
$\mathrm{PI}$
$\mathrm{PI}$

. polymeric photoinitiators

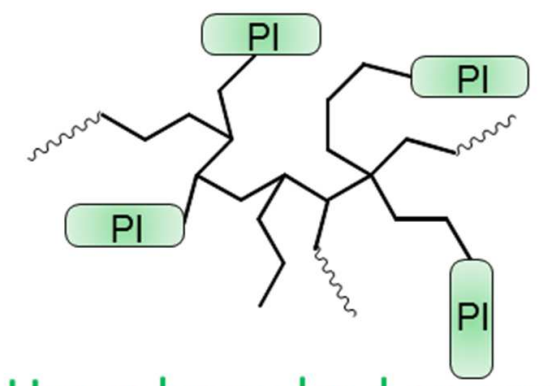

Multifunctional...

Hyperbranched or cross-linked...

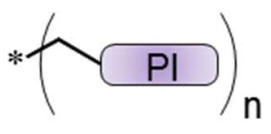

